Published in final edited form as:

Compr Physiol. 2015 January ; 5(1): 119-146. doi:10.1002/cphy.c140030.

\title{
Sympathoneural and Adrenomedullary Responses to Mental Stress
}

\author{
Jason R. Carter ${ }^{1}$ and David S. Goldstein ${ }^{2}$ \\ ${ }^{1}$ Department of Kinesiology and Integrative Physiology, Michigan Technological University, \\ Houghton, MI \\ ${ }^{2}$ Clinical Neurocardiology Section, Clinical Neurosciences Program, Division of Intramural \\ Research, National Institutes of Health, Bethesda, MD
}

\begin{abstract}
This concept-based review provides historical perspectives and updates about sympathetic noradrenergic and sympathetic adrenergic responses to mental stress. The topic of this review has incited perennial debate, because of disagreements over definitions, controversial inferences, and limited availability of relevant measurement tools. The discussion begins appropriately with Cannon's "homeostasis" and his pioneering work in the area. This is followed by mental stress as a scientific idea and the relatively new notions of allostasis and allostatic load. Experimental models of mental stress in rodents and humans are discussed, with particular attention to ethical constraints in humans. Sections follow on sympathoneural to mental stress, reactivity of catecholamine systems, clinical pathophysiologic states, and the cardiovascular reactivity hypothesis. Future advancement of the field will require integrative approaches and coordinated efforts between physiologists and psychologists on this interdisciplinary topic.
\end{abstract}

\section{Keywords}

psychological stress; emotional stress; sympathetic nerve activity; catecholamine; blood pressure regulation; cardiovascular reactivity

\section{INTRODUCTION}

The topic of this review has incited perennial debate. Before delving into the scientific literature, it is necessary and appropriate to summarize briefly what the issues have been that have rendered sympathoneural and adrenomedullary responses to mental stress so contentious and challenging.

The first is definitions. For instance, should one split the "sympathoadrenal system" into sympathoneural and adrenomedullary components? In some stressful situations, the sympathoneural and adrenomedullary components of the autonomic nervous system seem to respond as a unit, as proposed originally by Walter B. Cannon in the early $20^{\text {th }}$ century. In

Address for Correspondence: Jason R. Carter, Ph.D., Department of Kinesiology and Integrative Physiology, Michigan Technological University, 1400 Townsend Drive, Houghton, MI 49931, Phone: (906) 487-2715, Fax: (906) 487-0985, jcarter@ mtu.edu. 
others, however, sympathoneural and adrenomedullary activities change differentially or even in opposite directions. In addition, how should stress, mental stress, emotional stress, and distress be defined and distinguished, if they are not synonymous? What is meant by "sympathoneural," when changes in sympathetic nerve traffic occur heterogeneously in the body? What are "responses" in the context of emotional stress? Are they evoked changes in nerve traffic, transmitter release, delivery of released transmitter to receptors, intra-cellular mechanisms in effector cells, or some complex combination?

A second issue is inferences that may be unjustified. From acute effects of emotional stress inferences have often been drawn about chronic effects. From responses of skeletal muscle sympathetic nerve traffic, inferences have been drawn about overall sympathoneural cardiovascular "tone." From results of laboratory experiments, inferences have been drawn about responses to emotional stress in real life.

A third issue is limited availability of relevant measurement tools. For instance, although all would agree that adrenaline (synonymous with epinephrine) secretion is a key determinant of responses to emotional stress, circulating levels of the hormone are below the detection limits of most available assays under baseline conditions, and relatively few studies have described adrenaline responses. Although it is likely that mental stress involves important responses in sympathoneural outflow to the kidneys, measuring these responses requires highly sophisticated techniques not available at most institutions; and no technique has been developed that can be used to assess sympathoneural responses to splanchnic organs. A preponderance of recent literature has been based on measures of sympathetic nerve traffic in accessible organs such as skeletal muscle and skin.

We are not listing these concerns here simply to acknowledge and then dismiss them and move on. Instead, we will return to them repeatedly when relevant in this review, so that readers stay apprised not only of the wealth of recent experimental and observational information but also of what remains controversial, poorly understood, or frankly unknown.

\section{HISTORICAL PERSPECTIVE}

Walter B. Cannon is widely credited for extending Claude Bernard's $19^{\text {th }}$ century concept of the "milieu interieur," the internal environment that remains remarkably constant despite the ever-changing external environmental conditions and is maintained by compensatory body processes [1, 2]. Cannon invented and popularized the term, "homeostasis." He also pioneered the study of the effects of physical and psychological threats on adrenal gland secretion [2,3]. To Cannon, adrenal secretion was essential for the cardiovascular and metabolic changes that prepare an organism for "fight-or-flight" (a phrase that Cannon coined) $[2,3]$.

Cannon theorized that the sympathetic nervous system and the adrenal gland work together as a functional unit in emergencies-possibly the first proposal of a "neuroendocrine" system. Cannon went so far as to suggest that the sympathetic nervous system releases the same chemical messenger as the adrenal gland--adrenaline [4]. Given the option of supporting the concept that sympathetic nerves release a substance other than adrenaline or 
that adrenaline is converted to a different substance in the target cells, he chose the latter view. In 1946, a year after Cannon died, U.S. von Euler correctly identified norepinephrine (synonymous with noradrenaline) as the main sympathetic neurotransmitter in cardiovascular regulation [5].

Hans Selye popularized stress as a scientific idea [6]. In a famous letter to Nature in 1936 [7] he described for the first time what he came to refer to as the "syndrome of just being sick." He injected an ovarian extract in rats for several months and found that the treatment resulted in peptic ulceration, enlargement of the adrenal glands, and atrophy of the thymicolymphatic apparatus. Rats that received injections of placebo also developed this pathologic triad. Throughout the experiment, the rats often avoided injection attempts or wriggled free and had to be chased around the laboratory with a broom. We now recognize that both the experimental and control animals underwent stress, which Selye proposed as a novel concept. Selye and his students later provided evidence that stress responses are related to the hypothalamic-pituitary-adrenocortical (HPA) axis [6, 8]. According to Selye's "doctrine of non-specificity," stress is the non-specific response of the body to any demand imposed upon it [6]. John Mason, a well-known psychiatrist, who also made pioneering contributions to the psychological stress field [9, 10], argued against Selye's concept [11]. The doctrine of non-specificity was not actually tested experimentally for about a half century, and it was refuted [12]. Nevertheless, Selye's notion of stress as non-specific syndrome persists and remains widely used today, as evidenced by extremely frequent references to "the stress response" on the internet.

\section{Stress, Allostasis, and Allostatic Load}

Current concepts view stress as a sensed threat to homeostasis [13, 14], with the responses having a degree of specificity, depending among other things on the particular challenge and on the organism's perception of and perceived ability to cope with the stressor [15].

After adequately sensitive assay methods of plasma levels of norepinephrine and epinephrine became available, evidence rapidly accumulated for different noradrenergic vs. adrenergic responses in different situations. A new concept began to emerge, in which sympathetic nervous noradrenergic outflows play key roles in appropriate distribution of blood volume and regulation of blood pressure and blood delivery to the brain. The meaning of "appropriate" varies with the setting, such as orthostasis, cold exposure, mild blood loss, locomotion, exercise, altered salt intake, and water immersion [12, 16]. Sympathetic adrenergic system activity responds to more global or metabolic threats, such as hypoglycemia, hemorrhagic hypotension, exercise beyond an anerobic threshold, asphyxiation, distress, and shock. Evidence has also accumulated for an association between norepinephrine and active escape, avoidance, or attack and an association between epinephrine and passive, immobile fear.

Thus, in contrast with Selye's doctrine of non-specificity, according to the allostatic concept of stress responses, activities of effector systems are coordinated in relatively specific patterns, including neuroendocrine patterns. These patterns serve different needs, and the sympathetic noradrenergic and adrenergic systems play important roles in many of them. 
Although the idea of homeostasis might suggest a set of "goal" values for certain variables, ranges of acceptable values are now recognized to be decidedly inconstant. There are diurnal variations in body temperature, heart rate, and blood pressure. In addition, adaptations to different stressors include alterations in acceptable levels for monitored variables. Sterling and Eyer introduced the term, "allostasis," to describe the attainment of stability by natural alterations within acceptable ranges of variables attending the adjustments of the cardiovascular system during rest and activity [17]. The brain is the site at which effects of most stressors are sensed and appropriate coordinated behavioral and neuroendocrine responses initiated. Adaptations involving allostasis to cope with real, simulated, or imagined challenges are determined by genetic, developmental, and experiential factors. The low grade fever attending viral infections is an example of an allostatic change.

While they may be effective for a short interval, over time allostatic alterations may have cumulative adverse effects, via wear and tear on the effectors. For instance, chronic elevation of blood pressure to ensure adequate blood flow to the brain might eventually lead to atherosclerosis and stroke or coronary occlusion. The term, "allostatic load," has been used to denote adverse effects of cumulative wear and tear.

According to one systems concept of stress, the body possesses homeostatic comparators, called "homeostats" [15]. Each homeostat compares information supplied by a sensor with a setpoint for responding, determined by a regulator or set of regulator mechanisms. A sufficiently large sensed discrepancy between afferent information about the level of the monitored variable and the setpoint for responding elicits altered activities of effectors, the actions of which decrease the discrepancy in the monitored variable [18]. Whether comparator homeostats are actually required for allostatic adjustments may be questioned, and this has not yet been formally addressed. The reader is referred to a number of reviews on the topic of principles by which human physiologic homeostatic systems operate $[15,18]$.

Our conception of "distress" is that it is a form of stress with additional characteristicsconsciousness, aversiveness, instinctively communicated signs, and adrenal stimulation [15, 18]. This definition avoids the circularity inherent in defining distress by a pathologic pattern. Because of these characteristics, distress is tantamount to emotional distress. On the other hand, "mental" stress may or may not be distressing.

\section{EXPERIMENTAL MODELS OF MENTAL STRESS}

\section{Rodent Models}

Advantages of rodent experimental models include: (1) more invasive techniques that in some instances allow for continuous recording of key variables, (2) highly controlled and standardized environments, (3) controlled and chronic mental stressors that cannot be applied ethically in humans, and (4) the shorter lifespan of rodents allowing for a more costeffective approach to examining chronic stress.

Table 1 lists some laboratory manipulations that have been used as acute mental stressors in rodents. Some of these bear further comment. A commonly used method is air-jet stress. Air-jet stress protocols typically direct $\sim 20$ psi of compressed air to the head or face, from as 
little as a second to as much as several minutes, typically with the animals unrestrained.

Exposure to air-jet stress consistently increases heart rate, blood pressure, and both renal and lumbar sympathetic nerve traffic [19-22].

In rodents, restraint or immobilization evokes marked increases in sympathetic nerve traffic and plasma catecholamine levels [23, 24]. During tube restraint, the animal is permitted to move the limbs and head freely but is not able to move forward or backward or to turn around. During immobilization, the animal's limbs are kept immobile with paws or limbs taped or plastered to a surface, and only the head can move freely.

Transferring a mouse to a dirty cage occupied previously by a different mouse increases the heart rate and blood pressure and induces neuronal activation in several central autonomic regulatory areas including the nucleus of the solitary tract (NTS), the rostral ventrolateral medulla (RVLM), and the paraventricular nucleus of the hypothalamus (PVN) [25].

Acute shaking typically utilizes a cage attached to a shaking platform. As for airjet exposure, an advantage of this approach is that the stressor can be delivered without physical contact with an investigator prior to the test. Other rodent models of acute stress include electric shock to the tail or foot [26], forced swimming [27], sleep deprivation [28], noise [29], and cold exposure [30]. These generally evoke tachycardia, increased blood pressure, and sympathoneural activation.

In recent years, the use of acute laboratory stressors in rodents as a means to model autonomic effects of emotional stress in humans has been questioned. While all of the above models involve robust physiological alterations with pathophysiological consequences, it has been argued that they have limited generalizability to stressors encountered in a rodent's natural environment. Recently there has been an increase in the number of studies utilizing manipulations of the social situation. One such manipulation is the resident-intruder, in the social defeat test. This involves introduction of an experimental rodent in the territory of a dominant male, typically of the same species [31]. The dominant rodent aggressively attacks the intruder within a minute. In most experiments, the social interaction is terminated by the investigator when the intruder demonstrates signs of submission. The two animals are then separated by a wire mesh screen that allows them to see, hear, and smell each other.

Depending on the experimental design, the social defeat can be acute (minutes to hours) or chronic (days to weeks). Acute social defeat elicits robust increases in heart rate, blood pressure, catecholamines, and glucocorticoids and can even evoke cardiac arrhythmias [32]. Chronic social defeat is associated with lasting autonomic and endocrine responses. Chronic social defeat also disrupts circadian modulation of measures of autonomic outflows [33].

\section{Non-Human Primate Models}

Although rodent models enable controlled and standardized environments, one may question the applicability of laboratory rodent models to mental stress in humans, because of the roles of higher cortical processing and complex psychological processes in primates. On the other hand, primate research involving laboratory mental stressors such as a controlled social defeat involve well known ethical concerns. Sapolsky and colleagues have studied primates in their natural environments [8]—e.g., wild baboons in Kenya. The research has revealed 
that social hierarchy importantly influences neuroendocrine function, with "low rank" demonstrating a profile that typically includes elevated glucocorticoids, higher blood pressure, tachycardia, immunosuppression, and reduced levels of gonadal hormones [34]. Previously "dominant" baboons that transition to lower rank during social reorganization also evince physiological indices of psychosocial stress. Unfortunately, the line of research about social stress in primates studied in naturalistic settings has so far not adequately explored sympathoneural and adrenomedullary association with the physiological responses.

\section{Human Models of Acute Laboratory Mental Stress}

Table 2 highlights some of the more commonly used acute laboratory approaches in humans for assessing sympathoneural or adrenomedullary effects of emotional stress.

Mental arithmetic requires a subject to perform a series of additions or subtractions. The Stroop color-word conflict test involves verbal or nonverbal identification of a color that is embedded in the name of either a similar or different color (i.e., the word, "red," displayed in green font). These tests often are done in the context of other experimental factors such as time pressure, harassment by the experimenter, or monetary incentive. Much of the sympathoneural and adrenomedullary data related to acute mental stress have utilized one of these two experimental approaches. Sympathetic neural responsiveness does not seem to differ between mental arithmetic and Stroop testing [35].

In addition to mental arithmetic and Stroop testing, speech tasks and delayed auditory feedback have been used to elicit acute laboratory mental stress. During a speech task the subject is given a controversial topic and asked to give a 5-10 minute speech on the topic. Subjects typically are provided 5-15 minutes to prepare for the speech, and both the speech preparation and actual speech are analyzed, because both are associated with robust autonomic responses. Most studies that have utilized a speech task in conjunction with the Stroop test or mental arithmetic have found that the speech task yields greater reactivity [36]; however, reproducibility of the various responses is a problem (discussed in a later section).

Delayed auditory feedback is a less commonly used mental stressor that has been shown to elicit sympathoneural excitation [37]. Delayed auditory feedback is conducted by having subjects rapidly and accurately read a book aloud for 5-10 min while listening to their own voices with a $200 \mathrm{~ms}$ delay.

In recent years, several studies have used the International Affective Picture System (IAPS) to elicit a mental stress. In the IAPS test subjects view neutral or emotionally charged images, the latter being "positively charged" (e.g., erotica) or "negatively" charged (e.g., depictions of mutilation). Whereas hemodynamic responses to IAPS have been widely reported, sympathoneural responses to IAPS been studied only relatively recently. Carter et al. [38] reported that mental arithmetic increased skeletal muscle sympathetic nerve activity while negatively charged pictures did not; and Brown et al. [39] found that both negatively and positively charged IAPS pictures increased skin sympathetic nerve activity. An advantage of the IAPS approach is that it poses a reproducible stressor, as opposed to mental 
arithmetic, the Stroop test, or speech tasks that involve emotional, cognitive, and social psychological aspects.

Some have suggested that various exercise tests, cold pressor test, and third molar extracts represent approaches that provides insight into mental stress. In the cold pressor test, a subject's hand is immersed in a bucket of ice water for about 2 minutes. Perceived pain ratings during the cold pressor test are associated with blood pressure reactivity. Moreover, there is evidence suggesting that cardiovascular reactivity to cold pressor is augmented when subjects are forewarned by the investigator of the task difficulty and expected pain [36]. Most investigators, however, classify cold pressor test as more of a physical or thermal stress than a mental stressor. Cardiovascular reactivity to other laboratory mental stressors and to the cold pressor test are not consistently related [36].

Exercise testing can take various forms (e.g., isometric handgrip, lower body, whole body). Most investigators agree that data collected during exercise stress are too complex to use as an experimental model of mental stress. Autonomic indices immediately before exercise (i.e., anticipation) represent a potential model for examining mental stress or central command, although very little research has been done to assess intra-individual reliability of such an approach [36].

Third molar extraction has been utilized as a model of mental stress [40, 41] that is real-life, planned, and ethical. Various cardiovascular measures and plasma levels of catecholamines and other compounds can be assessed before, during, and after the procedures. Moreover, responses to extractions on one side using one experimental manipulation can be compared to responses on the other side using a different experimental manipulation on a different day. Responses to distress, physical trauma, and pain are complex in this setting, but to some extent they can be assessed differentially, e.g., by conscious sedation used a benzodiazepine during one session. This type of study is rare in mental stress literature but relatively common in pain literature.

\section{Human Models of Sudden, Unexpected Mental Stress}

Noninvasive monitoring of heart rate and in some cases blood pressure has occasionally been done at the time of exposure to sudden, unexpected mental stressors such as earthquakes. Obtaining more direct assessments in these situations is either impractical or in some cases impossible with currently available methodologies. Relationships of the physiological changes to sympathoneural or adrenomedullary activities are unclear [42].

Imposing sudden and unexpected mental stress in a laboratory setting is possible through deception techniques, but such approaches are considered unethical. This was not always the case. A review by Roddie [43] highlights some of the controversial mental stress studies performed in the 1950-60's in which the primary aim was to assess blood flow responsiveness during a "hoax" protocol. In one of the more infamous studies the experimenters injected a harmless saline injection into subjects but claimed that a potentially fatal drug had been injected [44]. Another hoax involved experimenters whispering loud enough for subjects to hear about unintended blood loss from the brachial artery and disagreement about whether or not to stop the experiment [45]. There was even a study in 
which an individual ran into the laboratory and exclaimed that there was a fire in the subject's office [46].

\section{Human Models of Chronic Mental Stress}

Imposing chronic mental stress experimentally in humans is unethical, but natural, chronic, presumed mental stressors have been studied. Examples are socioeconomic stress, job strain, caregiver stress, panic disorder, and post-traumatic stress disorder. Several studies have attempted to explore aspects of autonomic activities in these situations; however, the primary dependent measures have been non-specific and indirect, such as heart rate or blood pressure [47-50]. Naturalistic chronic mental stress study designs are complex and difficult to conduct, they rarely take into account factors such as habituation and resilience, and they involve inherent potential for subject self-selection bias. For instance, a study of adverse health outcomes in air traffic controllers did not take into account the possibility that people with particular atrisk personalities become air traffic controllers [51].

\section{SYMPATHETIC NEURAL REACTIVITY TO MENTAL STRESS}

\section{Sympathetic Microneurography}

Microneurography is a means to assess sympathetic nerve traffic directly. The technique involves insertion of a tungsten microelectrode into an available peripheral nerve. It is the only method available for direct recording of post-ganglionic sympathetic traffic in humans. Both skin sympathetic nerve activity (SSNA) and muscle sympathetic nerve activity (MSNA) can be recorded from accessible nerves in the upper (i.e., radial, medial, ulnar nerves) and lower (i.e., peroneal, tibial nerves) limbs [52]. Internal organs are not accessible to this technique in humans. Regional norepinephrine spillover (discussed in the next section) and microneurography have been viewed as complementary techniques [53].

\section{Early Studies of MSNA Responsiveness to Laboratory-Based Mental Stress}

The first recordings of MSNA during mental stress were reported in 1972. Delius et al. [54] examined arterial blood pressure and MSNA responses to mental stress during 6 sessions in 4 subjects. They reported an increase of arterial blood pressure and decrease of MSNA in 5 of the 6 sessions (one session demonstrated no change of MSNA). Wallin et al. [55] extended this work by examining MSNA responses to mental stress during 15 sessions in 9 subjects and reported inconsistent results. In nearly all the trials, blood pressure increased regardless of MSNA responses. Figure 1 depicts original recordings by Wallin and colleagues [55].

For nearly 15 years afterward there was a paucity of research examining MSNA during mental stress. This was revived by findings of Anderson et al. [56] about divergent MSNA responses to mental stress in the arm and leg. Simultaneous microneurographic recording demonstrated an increase of MSNA in the leg but not in the arm. Since the findings of Anderson et al. [56], there have been numerous studies examining MSNA responses to mental stress. Table 3 provides a summary of 55 studies so far that have used microneurographic techniques to investigate sympathetic neural responsiveness to acute 
laboratory-based mental stress. The remainder of this section discusses some of these studies.

\section{MSNA Variability to Laboratory-Based Mental Stress}

Sympathetic neural reactivity studies routinely include a variety of non-pharmacologic "sympathoexcitatory" maneuvers. Depending on the study rationale and disease of interest, investigators utilize the cold pressor test, isometric handgrip exercise, post-exercise ischemia, voluntary apnea, head-up tilt, lower body negative pressure, the Valsalva maneuver, or other tests. Compared to these sympathoexcitatory maneuvers, mental stress is associated with tremendous variability in MSNA responses. Whereas disease states and most of the sympathoexcitatory maneuvers elicit robust and reproducible increases of MSNA, MSNA can increase, decrease, or remain unchanged in response to mental stress. This variability was observed in the early studies by Wallin et al. [55] and continues to be found to this day [57]. There has not been a single test-retest study about MSNA responsiveness to mental stress.

These findings lead to two questions. First, what is the rationale for studying MSNA responsiveness to mental stress? Second, what does the tremendous amount of interindividual variability of MSNA during mental stress mean when it comes to human health and disease? Investigators who have studied MSNA responses to mental stress have used three justifications.

The most common rationale focuses on the potential mechanistic implications as related to the well-published cardiovascular reactivity hypothesis, which receives attention later in this review. It is widely acknowledged that MSNA, governed by the baroreflex, is a modulator of acute arterial blood pressure regulation; however, during exposure to a stressor other reflexes such as the chemoreflex and central command substantially influence MSNA and consequently blood pressure. Mental stress can override baroreflex restraint of MSNA [58], as evidence by concurrently increased blood pressure and MSNA during baroreceptor stimulation evoked by phenylephrine. While it seems reasonable to suggest MSNA responsiveness to mental stress influences cardiovascular reactivity, there is little evidence to support this notion. The early work of Wallin et al. [55] reported increases in arterial blood pressure when MSNA increased, decreased, or did not change. More recently, Carter and Ray [57] reviewed data from 82 subjects across several studies and reported that changes in arterial blood pressure were not correlated with changes in MSNA (Figure 2).

The second justification for examining MSNA responses to mental stress is potential elucidation of mechanisms of emotion-induced hemodynamic changes. Halliwill et al. [59] reported a reduction of forearm MSNA during mental stress that was tightly correlated to reductions of forearm vascular resistance, suggesting MSNA as a contributor to the classic forearm vasodilation observed during mental stress; however, the authors also demonstrated $\beta$-adrenergic vasodilation during mental stress [59], and this could reflect concurrent adrenomedullary activation [60]. Given the heterogeneous MSNA responses reported by Anderson et al. [61] in the leg vs. arm, Carter et al. [62] examined forearm MSNA, leg MSNA, forearm blood flow, and calf blood flow responses to mental stress. Figure 3 shows that mental stress did not alter MSNA in either the forearm or leg but did elicit forearm 
vasodilation [62], which was not correlated with changes in forearm MSNA [62]. MSNA withdrawal is therefore not obligatory for forearm vasodilation during mental stress.

The third justification for examining MSNA responses to mental stress relates to catastrophic cardiovascular events such as sudden cardiac death, stroke, and myocardial ischemia. This rationale relies heavily on the assumption that peripheral MSNA (either from the leg or arm) translates to sympathoexcitation in other tissues and organs such as the heart that cannot be easily accessed via microneurography. There is some evidence to support such a concept $[63,64]$; however, changes in MSNA are unrelated to changes in cardiac norepinephrine spillover during mental stress [63], and there is no literature about simultaneous MSNA and adrenomedullary responses in this type of situation.

For many years it was assumed that perceived stress was a primary driver of MSNA variability during mental stress. More recent studies have not observed a correlation between perceived stress and MSNA responses to mental stress [38, 57]. All three studies examining this issue have used the same perceived stress scale $[35,38,57]-$ a simple $0-4$ scale that did not probe into particular types of stress.

Regulation of arterial blood pressure is notoriously complex, and given increasing appreciation of scientific integrative medicine [65], it is no longer acceptable to maintain that MSNA and arterial blood pressure are coupled in any simple way during mental stress. Yang et al. [66] recently reported that calf vasodilation during mental stress was negatively correlated with MSNA reactivity in men but not in women. This suggests that the transduction of MSNA to the vasculature during mental stress may be gender-related. Another motivation for increased attention to MSNA and vascular coupling is the divergent and unresolved MSNA responsiveness to mental stress between the arm and leg [56, 59, 62]. We do not yet understand the physiological significance of this divergence, and the role of forearm MSNA in the classic forearm vasodilation associated with mental stress remains unclear due to limited data $[56,59,62]$.

Future studies should incorporate adrenoceptor responsiveness and hormonal and autocrine factors that may interact importantly with sympathoneural activity in mediating hemodynamic responses to mental stress. There is a clear need to examine MSNA and vascular responsiveness to mental stress simultaneously with other key regulatory mechanisms, as difficult and complex as that might be. Such additional measurements might include circulating catecholamines, nitric oxide, endothelin, and other modulators of vascular reactivity. Very few studies have taken this approach, but the studies that have done so have been very informative. The simultaneous recording of cardiac norepinephrine spillover and MSNA by Wallin et al. [63] serves as an example. Another insightful study was conducted by Hjemdahl et al. [67], who reported that MSNA correlated strongly with femoral venous plasma norepinephrine concentrations and spillover at rest but not during mental stress (Figure 4).

\section{MSNA Recovery to Mental Stress}

In contrast to highly variable responses of MSNA during mental stress, responses after mental stress seem to be quite consistent. Several studies by multiple groups have shown 
that MSNA is elevated after mental stress when compared to resting baseline [35, 56, 62, 68-70]. Few studies have highlighted the post-recovery sympathoexcitation associated with acute laboratory mental stress, but this may be relevant given a meta-analysis of Chida and Steptoe [71] that suggests a role of cardiovascular recovery as a marker of cardiovascular risk. Post-mental stress increases in MSNA are observed in both the arm and the leg, despite a dissociation of arm vs. leg MSNA during mental stress [56]. The finding of robust increases of MSNA after mental stress in both limbs was replicated by Carter et al. [62], despite no changes of arm or leg MSNA during mental stress.

It is unclear how long sympathetic activation persists after cessation of mental stress. MSNA has been shown to be significantly elevated for up to $10 \mathrm{~min}$ of recovery [35]. Moreover, post-stress elevation of MSNA is associated with a reduction of heart rate compared to prestress levels [35]. Not all studies demonstrate post-mental stress bradycardia, but nearly all studies note a rapid reduction of heart rate back to pre-stress baseline levels during recovery [62]. The sympathoexcitation after mental stress might have cardiovascular prognostic implications, but this has not been sufficiently explored.

\section{SSNA during Laboratory-Based Mental Stress}

Despite well-known pallor and piloerection attending terror and SSNA being highly responsive to emotional stimulation [72], few studies have examined SSNA responses during mental stress. In 1997, two studies were performed in which SSNA was quantified during acute laboratory mental stress in individuals with Guillain-Barre syndrome [73] or palmoplantar hyperhidrosis [74]. Patients with Guillain-Barre syndrome had exaggerated SSNA burst frequency responses to mental arithmetic during the acute phase, but not during remission phase, compared to healthy controls. These differences were no longer present when SSNA was analyzed as a percent change response, which is the more acceptable approach to analyzing SSNA [73]. In patients with palmoplantar hyperhidrosis (Figure 5), divergent SSNA responses were dependent upon the recorded nerve fascicle [74].

Recently, Muller et al. [75] examined SSNA responses to mental stress in healthy men and women using a test-retest experimental paradigm. The authors reported that SSNA reactivity to mental stress within the same day (separated by $45 \mathrm{~min}$ ) and across days (separated by $\sim 1$ week) did not differ across trials. Moreover, intra-class correlation demonstrated test-retest reliability [75]. A strength of this study was the well-controlled thermal environment that included a tube-lined suit perfused at $34-35^{\circ} \mathrm{C}$ to ensure consistent normothermic conditions across the three mental stress trials. The authors chose to record peroneal SSNA [75]; given the divergent tibial and peroneal SSNA reported by Iwase et al. [74], it may be important to establish reproducibility with tibial SSNA.

While the majority of SSNA-mental stress studies have utilized mental arithmetic to elicit stress, Brown et al. [39] recently reported SSNA responsiveness to neutral and emotionallycharged images from the International Affective Picture System (IAPS; Figure 6). In contrast to mental arithmetic, the IAPS elicits what is believed to be a more isolated emotional stress, although even with this approach there are several dimensions of 'emotional' stress to consider. Brown et al. [39] reported a significant increase of SSNA in response to both positive images (erotica) and negative images (mutilation) when compared 
to neutral images. The augmentation of SSNA with IAPS [39] was not observed with MSNA [38]. Collectively, these studies [38, 39] confirm the prominent role that emotional stress plays in SSNA regulation and suggest that IAPS-induced emotional stress has a differential influence on SSNA and MSNA. Effects of IAPS-induced emotional stress on adrenomedullary activity have not been studied.

\section{MSNA, Noradrenaline Spillover, and Chronic Mental Stress}

Most mental stress studies using combined MSNA and regional norepinephrine spillover approaches have been performed in a controlled laboratory setting using a standard laboratory stressor (e.g., mental arithmetic). Using panic disorder as a model of chronic stress, Wilkinson et al. [76] and Lambert et al. [77] reported that multiunit MSNA is not different between panic patients and healthy controls. As depicted in Figure 7, the authors did note that in panic disorder MSNA firing was often in a "multiple spike" pattern [77]. The physiological significance of this pattern remains unclear, but a more recent study suggests that aberrant single unit firing patterns are associated with increased cardiac noradrenaline spillover [78]. Evidence to date points to minimal influence of anxiety or panic disorder on MSNA; moreover, one may query whether panic disorder patients provide a model of chronic mental stress.

There has been a tendency to assume that sympathetic neural responses observed during acute laboratory mental stress reflect those during chronic mental stress. There is no published evidence to support such a claim. We still do not have consensus on lab-to-life generalizability.

\section{CATECHOLAMINE REACTIVITY TO MENTAL STRESS}

\section{Overview of Endogenous Catecholamines}

The human body possesses three endogenous catecholamines - dopamine (DA), norepinephrine (NE, synonymous with noradrenaline), and adrenaline (synonymous with epinephrine, EPI). DA is well known to be a central neurotransmitter. Nigrostriatal DA depletion is a neurochemical hallmark of Parkinson disease (PD) $[79,80]$. DA in the brain is also well known to play key roles in psychological phenomena such as reward [81, 82], drug addiction [83], and mood [84]. Perhaps less well known, DA in the periphery acts as an autocrine-paracrine substance [85]. In humans, all of the DA in urine is derived from uptake of circulating DOPA [86]. DA exiting the proximal tubular cells acts on the same or nearby cells to augment sodium excretion [87]. Most of the DA synthesized in the body is formed in non-neuronal cells in splanchnic organs, not the brain or sympathetic nervous system [88]. DA in plasma has a complex origin from dietary sources and sympathetic nerves [89].

$\mathrm{NE}$ is the main sympathetic neurotransmitter in circulatory regulation. Because of the crucial role of NE in reflexive, sympathetically mediated vasoconstriction during orthostasis, failure to synthesize NE due to DA-beta-hydroxylase deficiency invariably produces profound orthostatic hypotension [90], which can be effectively reversed by treatment with the NE precursor L-threo-dihydroxyphenylserine [91]. NE is also a central neurotransmitter thought 
to be involved in vigilance and attention [92], memory of distressing events [93-96], nociception [97-99], and panic/anxiety [100].

Ever since Cannon's classic description about a century ago of a substance released from the adrenal gland of a cat exposed to a barking dog [101], EPI has been viewed as the "fight or flight" hormone, released in emergencies to maintain homeostasis (a word than Cannon coined). As such, we have focused the majority of our discussion on EPI responses to acute and chronic mental stress.

\section{Challenges in Studying Catecholamine Reactivity to Mental Stress}

EPI is a remarkably powerful hormone. In healthy adult humans, EPI infused at $3 \mathrm{ng} / \mathrm{min} / \mathrm{dL}$ into the brachial artery (corresponding to an estimated increment in the arterial plasma concentration of about $3 \mathrm{nM}$ ) more than doubles forearm blood flow [102]. As one would expect, under resting conditions arm venous plasma EPI levels are extremely low, with a wide normal range from about 4 to $80 \mathrm{pg} / \mathrm{mL}(0.02-0.44 \mathrm{nM})$. A major challenge in studying sympathetic adrenergic reactivity to mental stress is that arm venous EPI levels strain the limits of detection of most assay methods. Due to extraction of arterial EPI in passage through forearm tissues, arm venous EPI is about one-half of arterial EPI [103]; however, arterial plasma EPI is rarely measured in laboratory studies of effects of mental stress [104].

A second challenge is the experimental setting. Because of the ethics of informed consent, assurance of safety of research participants, and self-selection bias, laboratory psychological challenges may not reproduce the catecholamine reactivity that occurs in real-life mental stress. For instance, as depicted in Figure 8, playing a video game does not alter arterial or venous EPI levels [104], whereas exposure to the stress of third molar extraction increases venous EPI levels substantially [40]. Even third molar extraction is an anticipated distressing situation, and one may reasonably expect that EPI responses to real-life, unexpected, distressing situations would be even larger.

A third challenge is that the relationship between acute responses to single stressors and chronic responses to repeated stressors is modulated by factors such as habituation, dishabituation, classic conditioning, resilience, and allostatic load [16, 105-108].

\section{Classic Research on Catecholamine Reactivity to Mental Stress}

Experiments by Walter B. Cannon in the early 20th century demonstrated for the first time that a substance is secreted by the adrenal glands into the bloodstream during emotional stress. In 1911 he reported an experiment in which an instrumented cat was exposed to a barking dog. Blood taken from the vena cava of the stressed cat relaxed a rhythmically contracting intestinal strip in a bioassay preparation, and this relaxation was not observed in adrenalectomized cats.

Several years later, Cannon perfected a denervated heart preparation and used heart rate responses as a measure of the extent of adrenal secretion [109]. In studies spanning two decades he reported that a variety of severe stressors increase heart rate in this preparation and that bilateral adrenalectomies blunt or prevent the effect (Figure 9). He concluded that 
both "fight" and "flight" are associated with increased adrenomedullary secretion [2, 3, 110, $111]$.

As noted previously, Cannon considered the adrenal medulla and sympathetic nervous system to function as a unit to maintain homeostasis in emergencies. After the discovery by von Euler that NE and not EPI is the chemical messenger of the sympathetic nerves (an exception is that sympathetic cholinergic nerves mediate sweating [112]), assay methods were introduced that enabled separate assessments of noradrenergic and adrenergic reactivity to different stressors. The first chemical method for detecting catecholamines was colorimetric [113], based on the unusual susceptibility of catecholamines to oxidize to form a brownish solution, "adrenochrome." In 1949, von Euler and Hamberg introduced a colorimetric method to assay catecholamines in which adrenochrome is converted chemically to 1-methyl-3,5,6-trihydroxyindole [114]. Trihydroxyindole has characteristic fluorescent properties, and detection of the fluorescence provided the basis for several methods that proved adequate to measure catecholamine concentrations in tissues [115]. Another type of fluorimetric assay was based on the condensation of oxidized catecholamines with ethylenediamine $[116,117]$, and this enabled separate measurement of NE and EPI in urine [118] and plasma [119].

Studies in the 1960s at the Walter Reed Army Institute of Research reported on effects of 72-hour electric footshock avoidance sessions or conditioned emotional responses to shock in monkeys [120-122]. During regularly repeated sessions, increases in NE excretion were observed without concurrent increases in EPI excretion; however, when free shock variation was substituted for earned shocks, then both NE and EPI were markedly increased. These studies provided the first evidence that simple alterations of reinforcement contingencies can influence the pattern of endocrine responses to emotional stressors. The same group also evaluated catecholaminergic effects of classically conditioned responses in human subjects who had previously acquired conditioned avoidance responses, with the same punishment, electric shock to the calf [123]. There was evidence for classically conditioned increases in heart rate and blood pressure and decreases in skin electrical resistance, coupled with increases in urinary excretion of 17-hydroxycorticosteroids, NE, and EPI.

In contrast with predictions from Cannon's notion of "fight" and "flight," patterns of NE and EPI responses provide evidence for a catecholaminergic distinction between rage and terror. Ax [124] and Funkenstein [125] linked EPI with fear or anxiety and NE with anger or aggression. In professional hockey players and in neuropsychiatric patients, selective increases in NE excretion were found to accompany aggressive, active emotional displays; whereas selective increases in urinary EPI excretion were accompanied tense and anxious but passive emotional behaviors [126].

\section{Norepinephrine Spillover}

The plasma NE spillover technique is a means to quantify the rate of entry of NE into the venous drainage of an organ such as the heart. ${ }^{3} \mathrm{H}-\mathrm{NE}$ is infused i.v. to a steady state, which is attained rapidly because of the short half-time for disappearance of circulating $\mathrm{NE}$--about 1.5 minutes. Endogenously released NE decreases the specific activity of the ${ }^{3} \mathrm{H}$ norepinephrine, and the extent of decrease in specific activity between the arterial plasma 
and the venous plasma is a measure of NE spillover. "Total body" NE spillover has been estimated from the specific activity of ${ }^{3} \mathrm{H}-\mathrm{NE}$ in arterial plasma. Regional NE spillover has been measured in a variety of organs, including the heart, kidneys, splanchnic organs, brain, and limbs [127-130].

Measurement of regional NE spillover takes into account the regional clearance of NE from the plasma as a determinant of the arteriovenous difference in plasma NE levels. On the other hand, it does not separate NE release from neuronal reuptake via the cell membrane NE transporter (Figure 10). One means to assess separately NE reuptake is by concurrent measurement of the specific activity of 3,4-dihydroxyphenylglycol (DHPG), the main neuronal metabolite of NE. Briefly, if there were no neuronal reuptake of endogenously released NE, NE spillover would overestimate NE release. In this situation, however, the specific activity of ${ }^{3} \mathrm{H}-\mathrm{DHPG}$ would be the same in the arterial and venous plasma. Concurrent measurements of endogenous and tracer-labeled catechols therefore provide a more accurate assessment of regional sympathetic nerve activity than measurement of $\mathrm{NE}$ spillover alone [131, 132]. To our knowledge, regional sympathetic nerve traffic and NE release estimated by measurements of endogenous and tracer-labeled catechols have not been assessed during mental stress.

\section{Disorders Involving Catecholamine Reactivity to Mental Stress}

It is very difficult to evaluate catecholamine reactivity to mental stress in a manner that (1) is independent of physical activity, which would be expected to increase sympathetic noradrenergic outflows and plasma NE levels differentially with respect to sympathetic adrenergic outflows and plasma EPI levels [133, 134]; (2) involves real-life distress, as opposed to laboratory challenges that are not particularly distressing [104]; (3) includes baseline measures prior to the stress [40]; and (4) takes into account factors such as systemic hemodynamics [135], posture [136], room temperature [137], meal ingestion [138, 139], the state of glycemia [140,141], which differentially affects sympathetic adrenergic outflow, and medications [142, 143]. With these limitations in mind, the following discussion highlights particular areas in which catecholamine reactivity to mental stress may play a role in the pathogenesis of a variety of disorders.

Takotsubo cardiomyopathy-Takotsubo cardiomyopathy is a relatively recently recognized acute, reversible form of heart failure that is characterized by hypokinesia of the left ventricular apical myocardium [144]. Contraction of the basal myocardium during systole gives the heart the appearance of a takotsubo, a Japanese ceramic pot used for trapping octopus. The condition is especially common in post-menopausal, acutely distressed women [145].

Takotsubo cardiomyopathy is associated with drastically increased plasma levels of catecholamines-especially EPI [146]. High circulating levels also of NE and of 3,4dihydroxyphenylglycol, the main neuronal metabolite of NE, indicate substantially increased sympathetic noradrenergic outflows [147].

Patients with takotsubo cardiomyopathy have decreased "uptake" and accelerated "washout" of ${ }^{123}$ I-metaiodobenzylguanidine-derived radioactivity in the affected myocardium [148- 
151]. This pattern might reflect increased cardiac sympathetic outflow, with high local NE and EPI concentrations competing with ${ }^{123}$ I-metaiodobenzylguanidine for neuronal uptake via the cell membrane NE transporter [152] or decreased ability of intra-neuronal vesicles to take up and retain ${ }^{123}$ I-metaiodobenzylguanidine. Increased cardiac sympathetic outflow, decreased neuronal reuptake, and excessive net leakage of NE from vesicular stores can explain augmented arterial-coronary sinus increments of plasma NE levels in takotsubo cardiomyopathy [153].

Why would high circulating EPI concentrations cause or contribute to the myocardial stunning attending takotsubo cardiomyopathy? According to one proposal [154], when EPI levels at myocardial beta- 2 adrenoceptors exceed a certain threshold, the mechanism of intracellular signal trafficking in the ventricular cardiomyocytes switches from the stimulatory $\mathrm{G}_{\mathrm{s}}$ protein to the inhibitory $\mathrm{G}_{\mathrm{i}}$ protein. In support of this notion, an in vivo rat model was reported recently by the same group [155] in which bolus i.v. injection of EPI produced reversible apical hypokinesia and basal hypercontractility found clinically, with the effect prevented by $\mathrm{G}_{\mathrm{i}}$ inactivation by pertussis toxin. On the other hand, $\mathrm{G}_{\mathrm{i}}$ inactivation increased mortality in the rat model. The authors have suggested that EPI-specific beta-2 adrenoceptor-mediated $\mathrm{G}_{\mathrm{i}}$ signaling may have evolved to limit catecholamine-induced myocardial toxicity during acute stress [155]. Figure 11 provides a concept diagram depicting proposed mechanisms of takotsubo cardiopathy.

Ventricular arrhythmias-Mental stress has long been thought to be associated with acute myocardial ischemia [156], myocardial infarction [157], and sudden cardiac death from ventricular arrhythmias $[158,159]$. The sympathetic noradrenergic system has been implicated as a factor linking mental stress with these morbid outcomes [160, 161].

The recent description of catecholaminergic polymorphic tachycardia (CPVT) helps solidify this link. CPVT is an inherited arrhythmia syndrome that often manifests as episodes of syncope in the first or second decade of life and predisposes to unexplained sudden cardiac death in young adulthood. Mutations of the gene encoding the ryanodine receptor RYR2 account for about $70 \%$ of CPVT cases and cause the autosomal dominant form of the disease $[162,163]$. The mutations lead to disruption of intracellular cAMP-induced aberrant $\mathrm{Ca}^{++}$release from the sarcoplasmic reticulum into the cytoplasm. Beta-adrenoceptor activation, which increases cAMP generation, may therefore precipitate a pathogenic positive feedback loop in which a ventricular arrhythmia rapidly increases cardiac sympathetic and adrenomedullary hormonal system outflows, in turn exacerbating aberrant $\mathrm{Ca}^{++}$release.

A case report illustrates the risk of mental stress evoking morbid manifestations of CPVT [164]. A 14-year-old boy suffered a cardiopulmonary arrest after attempting to invite a girl to the school dance. The presenting cardiac rhythm, induction of ventricular arrhythmias during an exercise stress test, and genetic testing confirmed the diagnosis of CPVT.

Beta-adrenoceptor blockers are a mainstay of treatment for CPVT but can be ineffective in preventing cardiac events [165]. An automated defibrillator may have to be implanted. Treatment for CPVT also includes left cardiac sympathectomy [166-168]. Plasma levels of 
catecholamines have not yet been assessed in CPVT, with or without therapeutic cardiac denervation. Compared to exercise testing, i.v. EPI infusion testing is specific but insensitive in diagnostic evaluation of CPVT [169].

Sympathoadrenal imbalance and fainting-Fainting reactions (vasovagal syncope $[170,171]$, vasodepressor syncope $[172,173]$, neurocardiogenic syncope [174], reflex syncope) constitute the most common cause of transient loss of consciousness in adults. Emotional stress may be an important contributor to syncope.

Fainting reactions can occur in the absence of cardiac innervation, such as after cardiac transplantation [171, 175-177], indicating that they do not necessarily depend on altered cardiac sympathetic or vagal outflow or on "collapse firing" of intra-cardiac baroreceptors in the setting of hyper-contractility and low cardiac filling volume [178]. Although there is often prominent bradycardia or even asystole at the time of loss of consciousness, hypotension often precedes the bradycardia [179].

There is substantial but inconsistent literature about whether fainting reactions are associated with decreased [180-184] or unchanged [185] skeletal muscle sympathetic outflow as measured by peroneal microneurography.

In stark contrast, all studies about plasma EPI have reported high EPI levels associating with fainting [60, 173, 186-195]. As outlined in Figure 12, these findings fit with the concept of "sympathoadrenal imbalance" before neurocardiogenic syncope [60]. According to this concept, EPI, via stimulation of beta-2 adrenoceptors in skeletal muscle arteriolar walls, decreases skeletal muscle vascular resistance, effectively shunting blood to the limbs at the expense of brainstem perfusion. Normally, reflexive increases in sympathetic noradrenergic outflow counter this effect; however, in fainting there is restraint of sympathetic noradrenergic outflow. This may be related to vasopressin [196-199] or inhibition of NE release for a given amount of skeletal muscle sympathetic nerve traffic [188, 200]—perhaps related to occupation of muscarinic receptors on sympathetic nerves [201, 202], nitric oxide [203], or endogenous opiates [188]. When the patient begins to feel distress, this evokes further EPI release and triggers a neurocirculatory positive feedback loop that leads rapidly to circulatory collapse. Figure 13 provides a concept diagram for shifts in blood flow distribution associated with tilt-induced syncope.

Hypertension-Inter-relationships among mental stress, catecholamines, and hypertension have long occupied the attention of researchers [204-206]. Because clinical hypertension is highly heterogeneous, it is likely that mental stress, via excessive catecholaminergic reactivity, participates only indirectly in the pathogenesis of hypertension [207]. Although neurochemical and neuropharmacologic testing can help identify patients with an augmented catecholaminergic contribution [208-211], this sort of profiling is rarely done in current clinical management of hypertensive patients.

A number of longitudinal studies in Finland have provided unique information about whether sympathetic noradrenergic or adrenergic hyperactivity predicts later development of essential hypertension. A 1982 study reported that middle-aged men with untreated, 
sustained essential hypertension had elevated plasma levels of both EPI and NE [212].

Almost a quarter century later, the same group reported that among young men who were unaware of their blood pressure status, resting pressure reflected both variation in resting arterial plasma NE and EPI and variation in cardiovascular and sympathetic responses to mental stress [213]. Moreover, an 18-year follow-up study provided evidence that plasma NE and EPI responses to stress predicted future blood pressure [214].

Patients with essential hypertension have been reported to have increased rates of entry of NE into the venous drainage ("spillover") in the heart, kidneys, cerebrovascular circulation, and body as a whole [128, 215-221]. The increases are most noticeable in relatively young ( $<45$ years old) patients. Increased NE spillover may have other determinants in addition to increased sympathetic nerve traffic, including decreased reuptake of release NE via the cell membrane NE transporter, stimulation of beta- 2 adrenoceptors on sympathetic nerves by elevated circulating EPI levels, and increased sympathetic nerve density [221].

The above findings rationalized development of renal sympathetic ablation by catheter-based radiofrequency ablation in the treatment of patients with refractory essential hypertension [222, 223]. Small clinical trials of this new treatment yielded remarkably positive results [224, 225], with substantial and sustained blood pressure reduction and no serious adverse events; however, in January, 2014, a prospective, randomized clinical trial was halted by the study sponsor for lack of efficacy.

Post-traumatic stress disorder-Post-traumatic stress disorder (PTSD) is associated with increased plasma NE [226], elevated urinary excretion rates of NE and EPI [227] and exaggerated catecholamine responses to yohimbine [228]. Indices of activity of the hypothalamic-pituitary-adrenocortical axis have been reported to be if anything decreased [229].

In a prospective study of civilian survivors of traumatic events, trauma survivors with and without PTSD had similar initial levels of plasma NE, urinary NE excretion, and NE:cortisol ratio in the emergency room [230]. Based on plasma and saliva cortisol, hourly urinary excretion of cortisol, plasma levels of adrenocorticotropin (ACTH), and leukocyte glucocorticoid receptor density, PTSD is not preceded by abnormal levels of any of these indices of hypothalamic-pituitary-adrenocortical axis function [231].

Future research in this area might benefit from movement away from the notion of a unitary "stress syndrome" and more attention specifically to the sympathetic adrenergic system. No study to date has assessed whether initial levels of EPI in plasma or urine predict later development of PTSD in survivors of traumatic events.

\section{THE CARDIOVASCULAR REACTIVITY HYPOTHESIS}

\section{Exaggerated Reactivity and Cardiovascular Disease}

The cardiovascular reactivity (CVR) hypothesis has been the subject of extensive research over more than 80 years. In 1932, Hines and Brown [232] reported a robust increase of blood pressure when a patient's hand was placed in a bucket of ice water--the cold pressor

Compr Physiol. Author manuscript; available in PMC 2017 January 30. 
test. Hines and Brown first suggested that CVR to the cold pressor test might predict later development of hypertension. In a subsequent study in 1934 [233], they reported CVR to cold pressor testing in 300 children and adolescents between the ages of 7 and 17 years. Two subsequent studies were performed in a subset of the original 300 subjects in 1961 and 1979 [234, 235]. On all three visits, subjects were classified as "hyperreactors" when the cold pressor test increased systolic blood pressure by $25 \mathrm{mmHg}$ or more or diastolic blood pressure by $20 \mathrm{mmHg}$ or more. Among individuals classified as hyperreactors in 1934 and $1961,71 \%$ were hypertensive at the 45 year follow up, while only $19 \%$ of normoreactors became hypertensive [235].

Several prospective epidemiologic studies have supported the concept of CVR as a risk factor for hypertension. A meta-analysis by Chida and Steptoe [71] provides perhaps the strongest evidence to date supporting the CVR hypothesis. The analysis reviewed data from 36 prospective studies about CVR to laboratory mental stress, delayed cardiovascular recovery, and future cardiovascular disease. As indicated in Figure 14, heightened CVR to acute laboratory mental stress was found to be associated with adverse cardiovascular outcomes, particularly hypertension [71]. According to this meta-analysis, blood pressure reactivity tends to be more predictive than heart rate reactivity. Cognitive stressors such as mental arithmetic and the Stroop color-word conflict test tend to have greater predictability than stress interviews, public speaking, emotional induction, or combined stressors. While CVR may be predictive of hypertension, it does not appear to predict coronary calcification or carotid intimal-medial thickness.

A novel aspect of this meta-analysis was the relationship between mental stress recovery and cardiovascular disease predictability. As depicted in Figure 15, delayed recovery of cardiovascular variables after mental stress seems to be predictive of cardiovascular disease. Delayed cardiovascular recovery is predictive not only with respect to blood pressure but also carotid intimal-medial thickness. Both the CVR and recovery effects reported in this meta-analysis remained significant when more conservative aggregated analyses were performed.

Some have proposed that CVR is more than simply a predictor and that exaggerated CVR is causally related to the development of hypertension and other cardiovascular diseases. This version of the CVR hypothesis posits that repeated bouts of acute mental stress and the consequent short-term tachycardia and hypertension have cumulative effects. A review by Schwartz et al. [236] suggests that the evidence is insufficient to support a causal role. Of particular concern to the authors are the issues of generalizability, lack of attention to environmental conditions and psychological predispositions, and highly variable durations and coping strategies. A more recent review [237] shares some of these concerns but also offers a more optimistic view regarding generalizability and strategies to overcome various limitations. The following sections focus on the concepts of reliability, generalizability, and ecological validity that are important for the CVR hypothesis and autonomic adjustments to mental stress. 


\section{Reproducibility and Aggregation}

The reproducibility of blood pressure and heart rate reactivity to mental stress is an obvious and important question. In general, studies have largely supported the view that CVR is reproducible, but the level of reproducibility is widely variable [36]. In an important metaanalysis, Swain and Suls [238] demonstrated reproducibility for both heart rate and blood pressure reactivity to various laboratory stressors, with the strongest reproducibility being observed for heart rate reactivity. Most test-retest paradigms have retested after one week or one month; reproducibility across longer intervals is less well established.

The meta-analysis by Swain and Suls [238] also revealed that aggregation of data across multiple stressors within a single laboratory session increased reproducibility across laboratory sessions. More recently, several reviews have emphasized the importance of aggregation in CVR reproducibility and suggested that aggregation of data improves reproducibility. Kamarack and Lovallo [36] highlight how test-retest reliability, with aggregated data across multiple sessions (i.e., multiple days), can explain up to an additional $15 \%$ of variance ( $\sim 66 \%$ to $\sim 81 \%$ variance) when compared to aggregated data across tasks from a single session.

In an 18-year follow-up study, Hassellund et al. [239] noted correlations ranging from 0.60.8 between cardiovascular and EPI responses during mental stress. The entry/follow-up correlation of systolic blood pressure during mental stress was significantly higher than during the cold pressor test. This important study suggested that cardiovascular and adrenomedullary responsiveness to mental stress are relatively stable individual characteristics.

Kamarack and Lovallo [36] caution that care should be taken when interpreting psychological stressors (i.e., mental arithmetic, Stroop color word conflict test, public speaking) and physical stressors (i.e., cold pressor test, acute exercise), citing limited or inconsistent evidence for associations between psychological and physical stressors. A fundamental assumption of the "aggregation" theory of CVR is that by using multiple tasks and sessions, the error variance is reduced. Increasing the diversity of the stress challenge might offer better modeling of complex real-life stressors. Prospective studies have reported that both mental stress and the cold pressor test have predictive value with regard to future risk of cardiovascular disease [71].

There is a paucity of prospective studies that have examined how variability across tasks plays into future risk of cardiovascular disease, particularly hypertension. An exception is a study by Flaa et al. [214], who found that arterial catecholamine concentrations during rest and exposure to laboratory stressor (mental arithmetic and the cold pressor test) independently predicted blood pressure at 18 years of follow-up. After adjusting for initial resting blood pressure, family history, body mass index, and systolic blood pressure during the stress test in a multiple regression analysis, the NE and EPI concentrations during mental arithmetic explained $12.7 \%$ of the variation of future systolic blood pressure.

In summary, the available literature generally supports the concept that CVR is reproducible and that aggregation across tasks or sessions enhances this reproducibility. While the 
evidence suggests that aggregation across a similar content domain (i.e., psychological stress) produces the greatest reproducibility, we would argue that inclusion of other content domains (e.g., the cold pressor test) might model better the complexity of real-life stressors. The next section will discuss generalizability, and the important role of aggregation in generalizability. There may be valuable inferences to be drawn from intra-individual variability between acute laboratory stressors across content domains.

\section{Generalizability and Ecological Validity}

Generalizability refers to the consistency between acute laboratory stressors (e.g., mental arithmetic, the Stroop color-word conflict test) and naturalistic stressors (e.g., public speaking, job strain, caregiving stress). Generalizability would suggest that individuals with high CVR to an acute laboratory mental stress would also be high reactors to real world ambulatory stress. Evidence for such generalizability remains controversial and is the primary impediment to the strongest interpretation of the CVR hypothesis (i.e., causal role).

In 1990, Pickering and Gerin [240] assessed the state of the CVR hypothesis. At that time there were only a limited number of studies that assessed CVR generalizability, and the authors questioned lab-to-life generalizability and suggested a need for further research. Between 1990 and 2003 a number of studies were led to an update of the generalizability of CVR [236]. After an extensive literature review, Schwartz et al. [236] concluded there is a lack of lab-to-life generalizability and suggested that CVR offers a poor methodology to study responses to real-world stressors. The authors acknowledged that aggregation led to modest improvements in generalizability [236]. They also suggested that attention to anticipatory and recovery responses to stress might also improve generalizability. Schwartz et al. [236] advocated for a shift towards naturalistic and environmental stressors, including job strain and socioeconomic status. We agree that the field would benefit from such a shift and suggest that caregiving, job strain, and social hierarchy be considered further. Such stressors have their own limitations. We are not yet prepared to yield that acute laboratory stressors are incapable of lab-to-life generalizability, and two recent reviews [36, 237] provide some new and relevant insights in this debate.

While many of the attempts to refute CVR generalizability have focused on the lack of laboratory generalizability with ambulatory measurements, Kamarack and Lovallo [36] suggest that a multilevel approach that accounts for within-subject variability of ambulatory measurements is important. In one study, Kamarack et al. [241] examined how self-report measurements of task demand and decisional control were associated with each ambulatory blood pressure recording taken over approximately one week. Both activity levels and posture were included as covariates in the analysis. The authors reported that laboratory CVR was unrelated to non-specific ambulatory blood pressure [241]. Individuals with exaggerated laboratory CVR did demonstrate larger increases of ambulatory blood pressure during periods of high task demand and low decisional control. In other words, high laboratory reactors had high ambulatory blood pressure but only during high task demand or low decisional control, suggesting that CVR generalizability may be facilitated by focusing on stressful naturalistic episodes. Kamarck and Lovallo [36] supported the concept that 
aggregation can improve generalizability and highlighted that many studies refuting the concept of generalizability have relied upon single-task comparisons.

Consistent with Kamarck and Lovallo [36], a recent review suggests that methodological issues may be contributing to the lack of lab-to-life generalizability reported in some studies. Zanstra and Johnston [237] critiqued the endpoints used to classify CVR in real life and highlighted that technological advances over the past decade are allowing more accurate assessment of naturalistic reactivity. The collection of 24-hour ambulatory heart rate or blood pressure data, in conjunction with data on self-perceived episodic stress levels, has been made easier by the proliferation of smartphones and other miniaturized handheld devices. Use of continuous, ambulatory finger plethysmography (i.e., Portapres) is readily available to provide even more accuracy on beat-to-beat blood pressure and self-reported stress. Of particular relevance, Johnston et al. [242] compared laboratory CVR with ambulatory CVR and accounted for self-reported negative emotions during the ambulatory recordings. They reported that laboratory CVR was associated with heart rate increases to negative emotions, even after controlling for physical activity and posture. These findings are consistent with Kamarack et al. [241] and demonstrate the need to account for the emotional ambulatory state when attempting to relate laboratory CVR with ambulatory measurements.

In sum, lab-to-life generalizability remains controversial. Using more modern technologies, evidence is emerging to suggest lab-to-life generalizability during episodic ambulatory stress. Aggregation and attention to recovery responses can enhance generalizability [36, $236,237]$. Recent technological advances in simultaneously obtaining ambulatory measurements with self-perceived stress may shed new light in the ongoing debate.

\section{FUTURE DIRECTIONS}

In this review we have presented historical perspective and a modern overview of sympathetic neural and adrenomedullary adjustments to mental stress. The primary focus has been on direct measures of sympathetic activity in humans (e.g., catecholamines, sympathetic nerve activity, NE spillover) and implications for a variety of clinical disorders. We have critiqued current methodologies and study designs. Laboratory-based approaches may be convenient and cost-effective, but some assumptions based on this format may be misguided.

This review has emphasized the longstanding and still controversial CVR hypothesis, which continues to be a primary rationale for many studies. While the CVR field has been tested in a much more detailed and rigorous fashion, psychologists driving this field have tended to oversimplify indices of autonomic activity, or ignore underlying autonomic mechanisms altogether. Likewise, autonomic physiologists seem to have failed to appreciate the psychological complexities and have used overly simplistic psychological tests [35, 57].

Moving forward, there needs to be much greater emphasis on drawing upon expertise in these two fields. Sympathetic adjustments to mental stress embody the interdisciplinary field of psychophysiology, yet the vast majority of published work on sympathetic adjustments to 
mental stress is by a cadre of investigators with expertise in only one of these two domains. Moreover, autonomic responsiveness to mental stress, and particularly sympathetic neural reactivity to acute laboratory mental stress, needs to undergo the same rigorous testing to which the CVR hypothesis has been subjected.

We acknowledge the difficulty associated with procedures such as microneurography or the cardiac NE spillover technique compared to simple measurements of heart rate and blood pressure reactivity. Nevertheless, given that there have been 55 published studies on MSNA reactivity to acute laboratory-based mental stress (the majority published within the last 1520 years), a deficiency has been the absence of test-retest studies on MSNA responsiveness to mental stress. In contrast, there have been numerous studies examining test-retest of CVR to acute laboratory mental stress [36]. The issue of whether MSNA responses to acute laboratory mental stress are reproducible seems particularly timely, given NIH Director Francis Collins's recent call for increased attention to reproducibility to ensure careful investment of our nation's medical research funding [243].

Other issues for future attention are lab-to-life generalizability and ecological validity as they pertain to sympathetic neural reactivity to mental stress. This will shift the field to consider novel approaches to assessing autonomic adjustments to sudden, unexpected mental stress and natural chronic mental stress. This review has provided examples of how we might approach such lab-to-life generalizability studies.

In parallel with proposed reproducibility and validity studies, it seems important and clinically relevant to expand our understanding of the inter- and intra-variability observed during acute mental stress. As outlined previously [244], is it reasonable to conclude that MSNA variability to mental stress provides a unique window of insight into hypertension or other cardiovascular diseases? More research attention to psychological states and traits appears warranted. For example, well established questionnaires such as the State-Trait Anxiety Inventory (STAI) can be incorporated immediately following the informed consent process [245]. Another questionnaire that we recommend for consideration would be the Positive and Negative Affect Schedule (PANAS-X), which provides indices of hostility, depression, and neuroticism among other psychological traits [246]. As outlined above in the discussion of the CVR hypothesis, recent research suggests that coping strategies can influence CVR to mental stress. Questionnaires assessing coping strategies or resilience would be particularly useful for autonomic physiologists.

Technical difficulties in measuring adrenomedullary activity by plasma EPI levels were surmounted three decades ago, yet studies in the area of autonomic responses to mental stress have not incorporated this component adequately. Future research would benefit from measurements of MSNA and plasma EPI in the same subjects. For instance, although MSNA is increased substantially in takotsubo cardiopathy [247], it may be that even more profound adrenomedullary activation [146] drives the cardiovascular abnormalities. As indicated in Figure 16, across a variety of stressors adrenomedullary responses seem to be linked at least as closely to responses of the hypothalamic-pituitary-adrenocortical system than of the sympathetic noradrenergic system [134]. 
We have tried to emphasize the value of integrated physiological approaches such as the concept of scientific integrative medicine [65]. We suggest increased attention to negative feedback loops, compensatory activation, and effector sharing. Moreover, when it comes to mental stress, we need to consider these complex mechanisms in the context of psychological perceptions and experiences.

Finally, there is a need to examine sympathetic neural and adrenomedullary adjustments to mental stress in the context of health disparities. While there has been a recent increase in autonomic mental stress research focused on sex differences, there has been very limited attention to racial, ethnic, and socioeconomic disparities in the field.

\section{REFERENCES}

1. Bernard, C. Introduction a l'Etude de la Medicine Experimentale. New York: McMillan; 1927.

2. Cannon, WB. The Wisdom of the Body. New York: W.W. Norton; 1939.

3. Cannon, WB. Bodily changes in pain, hunger, fear and rage. New York: D. Appleton \& Co.; 1929.

4. Cannon WB, Lissak K. Evidence for adrenaline in adrenergic neurones. Am J Physiol. 1939; 97:592-595.

5. von Euler US. A specific sympathomimetic ergone in adrenergic nerve fibres (sympathin) and its relations to adrenaline and nor-adrenaline. Acta Physiol Scand. 1946; 12:73-96.

6. Selye, H. Stress without Distress. New York: New American Library; 1974.

7. Selye H. A syndrome produced by diverse nocuous agents. Nature. 1936; 138:32.

8. Sapolsky, RM. Why zebra don't get ulcers: an updated guide to stress, stress-related disease, and coping. New York: W.H. Freeman and Company; 1998. p. 19-37.

9. Mason JW. A historical view of the stress field. J Human Stress. 1975; 1(2):22-36. concl.

10. Selye H. Confusion and controversy in the stress field. J Human Stress. 1975; 1(2):37-44.

11. Mason JW. A re-evaluation of the concept of 'non-specificity' in stress theory. J. Psychiatry Res. 1971; 8:323-333.

12. Pacak K, et al. Heterogeneous neurochemical responses to different stressors: A test of Selye's doctrine of nonspecificity. Am. J. Physiol. 1998; 275:R1247-R1255. [PubMed: 9756557]

13. McEwen B, Stellar E. Stress and the individual. Mechanisms leading to disease. Arch. Int. Med. 1993; 153:2093-2101. [PubMed: 8379800]

14. Goldstein DS, McEwen B. Allostasis, homeostats, and the nature of stress. Stress. 2002; 5(1):5558. [PubMed: 12171767]

15. Goldstein, DS. Adrenaline and the Inner World: An Introduction to Scientific Integrative Medicine. Baltimore, MD: The Johns Hopkins University Press; 2006.

16. Kvetnansky R. Stressor specificity and effect of prior experience on catecholamine biosynthetic enzyme phenylethanolamine N-methyltransferase. Ann. N. Y. Acad. Sci. 2004; 1032:117-129. [PubMed: 15677399]

17. Sterling, P., Eyer, J. Allostasis: a new paradigm to explain arousal pathology, in Handbook of Life Stress, Cognition, and Health. Fisher, J., Reason, J., editors. New York: Johns Wiley \& Sons Inc.; 1988. p. 629-649.

18. Goldstein DS. Concepts of scientific integrative medicine applied to the physiology and pathophysiology of catecholamine systems. Comp. Physiol. 2013; 3:1569-1610.

19. DiBona GF, Jones SY. Analysis of renal sympathetic nerve responses to stress. Hypertension. 1995; 25(4 Pt 1):531-538. [PubMed: 7721394]

20. Koepke JP, DiBona GF. High sodium intake enhances renal nerve and antinatriuretic responses to stress in spontaneously hypertensive rats. Hypertension. 1985; 7(3 Pt 1):357-363. [PubMed: 3997220]

Compr Physiol. Author manuscript; available in PMC 2017 January 30. 
21. Koepke JP, DiBona GF. Central beta-adrenergic receptors mediate renal nerve activity during stress in conscious spontaneously hypertensive rats. Hypertension. 1985; 7(3 Pt 1):350-356. [PubMed: 2860062]

22. Moffitt JA, et al. Olfactory bulbectomy attenuates cardiovascular sympathoexcitatory reflexes in rats. Am J Physiol Heart Circ Physiol. 2002; 283(6):H2575-H2583. [PubMed: 12388291]

23. Ngampramuan $\mathrm{S}$, et al. Activation of 5-HT(1A) receptors attenuates tachycardia induced by restraint stress in rats. Am J Physiol Regul Integr Comp Physiol. 2008; 294(1):R132-R141. [PubMed: 17959705]

24. Kvetnansky R, et al. Effect of handling and forced immobilization on rat plasma levels of epinephrine, norepinephrine, and dopamine-beta-hydroxylase. Endocrinology. 1978; 103(5):18681874. [PubMed: 748021]

25. Davern PJ, et al. Role of the sympathetic nervous system in Schlager genetically hypertensive mice. Hypertension. 2009; 54(4):852-859. [PubMed: 19667247]

26. Randall DC, et al. Sympathetic nervous activity and arterial blood pressure control in conscious rat during rest and behavioral stress. Am J Physiol. 1994; 267(5 Pt 2):R1241-R1249. [PubMed: 7977851]

27. Sgoifo A, et al. Different sympathovagal modulation of heart rate during social and nonsocial stress episodes in wild-type rats. Physiol Behav. 1999; 67(5):733-738. [PubMed: 10604845]

28. Perry JC, et al. Sympathetic and angiotensinergic responses mediated by paradoxical sleep loss in rats. J Renin Angiotensin Aldosterone Syst. 2011; 12(3):146-152. [PubMed: 21398399]

29. Hallback M, et al. Cardiovascular control in the Milan strain of spontaneously hypertensive rat (MHS) at "rest" and during acute mental "stress". Acta Physiol Scand. 1977; 99(2):208-216. [PubMed: 557279]

30. Kenney MJ, et al. Cold stress alters characteristics of sympathetic nerve discharge bursts. J Appl Physiol (1985). 1999; 87(2):732-742. [PubMed: 10444634]

31. Sgoifo A, Carnevali L, Grippo AJ. The socially stressed heart. Insights from studies in rodents. Neurosci Biobehav Rev. 2014; 39C:51-60.

32. Sgoifo A, et al. Social stress, autonomic neural activation, and cardiac activity in rats. Neurosci Biobehav Rev. 1999; 23(7):915-923. [PubMed: 10580306]

33. Meerlo $P$, et al. Long-lasting consequences of a social conflict in rats: behavior during the interaction predicts subsequent changes in daily rhythms of heart rate, temperature, and activity. Behav Neurosci. 1999; 113(6):1283-1290. [PubMed: 10636307]

34. Sapolsky RM. The influence of social hierarchy on primate health. Science. 2005; 308(5722):648652. [PubMed: 15860617]

35. Callister R, Suwarno NO, Seals DR. Sympathetic activity is influenced by task difficulty and stress perception during mental challenge in humans. J Physiol. 1992; 454:373-387. [PubMed: 1474496]

36. Kamarck TW, Lovallo WR. Cardiovascular reactivity to psychological challenge: conceptual and measurement considerations. Psychosom Med. 2003; 65(1):9-21. [PubMed: 12554812]

37. Matsukawa T, Sugiyama Y, Mano T. Increased muscle sympathetic nerve activity during delayed auditory feedback in humans. Jpn J Physiol. 1995; 45(5):905-911. [PubMed: 8713185]

38. Carter JR, Durocher JJ, Kern RP. Neural and cardiovascular responses to emotional stress in humans. Am J Physiol Regul Integr Comp Physiol. 2008; 295(6):R1898-R1903. [PubMed: 18784331]

39. Brown R, et al. Autonomic markers of emotional processing: skin sympathetic nerve activity in humans during exposure to emotionally charged images. Front Physiol. 2012; 3:394. [PubMed: 23060818]

40. Goldstein DS, et al. Circulatory, plasma catecholamine, cortisol, lipid, and psychological responses to a real-life stress (third molar extractions): effects of diazepam sedation and of inclusion of epinephrine with the local anesthetic. Psychosom. Med. 1982; 44:259-272. [PubMed: 7134364]

41. Dionne RA, Goldstein DS, Wirdzek PR. Effects of diazepam premedication and epinephrinecontaining local anesthetic on cardiovascular and plasma catecholamine responses to oral surgery. Anesth. Analg. 1984; 63:640-646. [PubMed: 6731889]

42. Eckberg DL. Sympathovagal balance: a critical appraisal. Circulation. 1997; 96(9):3224-3232. [PubMed: 9386196] 
43. Roddie IC. Human responses to emotional stress. Ir J Med Sci. 1977; 146(12):395-417. [PubMed: 344268]

44. Glover WE, Greenfield AD, Shanks RG. The contribution made by adrenaline to the vasodilatation in the human forearm during emotional stress. J Physiol. 1962; 164:422-429. [PubMed: 13948523]

45. Blair DA, et al. Excitation of cholinergic vasodilator nerves to human skeletal muscles during emotional stress. J Physiol. 1959; 148:633-647. [PubMed: 13801238]

46. Roddie IC. The role of vasoconstrictor and vasodilator nerves to skin and muscle in the regulation of the human circulation. Ann R Coll Surg Engl. 1963; 32:180-193. [PubMed: 13974599]

47. Cohen $\mathrm{H}$, et al. Power spectral analysis of heart rate variability in posttraumatic stress disorder patients. Biol Psychiatry. 1997; 41(5):627-629. [PubMed: 9046997]

48. Hemingway $\mathrm{H}$, et al. Does autonomic function link social position to coronary risk? The Whitehall II study. Circulation. 2005; 111(23):3071-3077. [PubMed: 15939818]

49. Jarczok MN, et al. Autonomic nervous system activity and workplace stressors--a systematic review. Neurosci Biobehav Rev. 2013; 37(8):1810-1823. [PubMed: 23891906]

50. Martinez JM, et al. Heart rate and blood pressure changes during autonomic nervous system challenge in panic disorder patients. Psychosom Med. 2010; 72(5):442-449. [PubMed: 20368476]

51. Cobb S, Rose RM. Hypertension, peptic ulcer, and diabetes in air traffic controllers. JAMA. 1973; 224:489-492. [PubMed: 4739607]

52. Vallbo AB, Hagbarth KE, Wallin BG. Microneurography: how the technique developed and its role in the investigation of the sympathetic nervous system. J Appl Physiol. 2004; 96(4):1262-1269. [PubMed: 15016790]

53. Esler M. The 2009 Carl Ludwig Lecture: Pathophysiology of the human sympathetic nervous system in cardiovascular diseases: the transition from mechanisms to medical management. J Appl Physiol. 2010; 108(2):227-237. [PubMed: 19940096]

54. Delius W, et al. Manoeuvres affecting sympathetic outflow in human muscle nerves. Acta Physiol Scand. 1972; 84(1):82-94. [PubMed: 5029386]

55. Wallin BG, Delius W, Hagbarth KE. Comparison of sympathetic nerve activity in normotensive and hypertensive subjects. Circ Res. 1973; 33(1):9-21. [PubMed: 4765704]

56. Anderson EA, Wallin BG, Mark AL. Dissociation of sympathetic nerve activity in arm and leg muscle during mental stress. Hypertension. 1987; 9(6 Pt 2):III114-III119. [PubMed: 3596778]

57. Carter JR, Ray CA. Sympathetic neural responses to mental stress: responders, nonresponders and sex differences. Am J Physiol Heart Circ Physiol. 2009; 296(3):H847-H853. [PubMed: 19168718]

58. Anderson EA, Sinkey CA, Mark AL. Mental stress increases sympathetic nerve activity during sustained baroreceptor stimulation in humans. Hypertension. 1991; 17(4 Suppl):III43-III49. [PubMed: 2013492]

59. Halliwill JR, et al. Forearm sympathetic withdrawal and vasodilatation during mental stress in humans. J Physiol. 1997; 504(Pt 1):211-220. [PubMed: 9350631]

60. Goldstein DS, et al. Sympathoadrenal imbalance before neurocardiogenic syncope. Am. J. Cardiol. 2003; 91(1):53-58. [PubMed: 12505571]

61. Anderson EA, et al. Enhanced forearm blood flow during mental stress in children of hypertensive parents. Hypertension. 1987; 10(5):544-549. [PubMed: 3666867]

62. Carter JR, Kupiers NT, Ray CA. Neurovascular responses to mental stress. J Physiol. 2005; 564(Pt 1):321-327. [PubMed: 15705649]

63. Wallin BG, et al. Simultaneous measurements of cardiac noradrenaline spillover and sympathetic outflow to skeletal muscle in humans. J Physiol. 1992; 453:45-58. [PubMed: 1464839]

64. Wallin BG, et al. Renal noradrenaline spillover correlates with muscle sympathetic activity in humans. J Physiol. 1996; 491(Pt 3):881-887. [PubMed: 8815219]

65. Goldstein DS. Concepts of scientific integrative medicine applied to the physiology and pathophysiology of catecholamine systems. Compr Physiol. 2013; 3(4):1569-1610. [PubMed: 24265239] 
66. Yang H, Drummer TD, Carter JR. Sex differences in sympathetic neural and limb vascular reactivity to mental stress in humans. Am J Physiol Heart Circ Physiol. 2013; 304(3):H436-H443. [PubMed: 23203970]

67. Hjemdahl P, et al. Muscle sympathetic nerve activity and norepinephrine release during mental challenge in humans. Am J Physiol Endocrinol Metab. 1989; 257:E654-E664.

68. Carter JR, Cooke WH, Ray CA. Forearm neurovascular responses during mental stress and vestibular activation. Am J Physiol Heart Circ Physiol. 2004

69. Carter JR, Lawrence JE. Effects of the menstrual cycle on sympathetic neural responses to mental stress in humans. J Physiol. 2007; 585(Pt 2):635-641. [PubMed: 17932154]

70. Kamiya A, et al. Head-down bed rest alters sympathetic and cardiovascular responses to mental stress. Am J Physiol Regul Integr Comp Physiol. 2000; 279(2):R440-R447. [PubMed: 10938230]

71. Chida Y, Steptoe A. Greater cardiovascular responses to laboratory mental stress are associated with poor subsequent cardiovascular risk status: a meta-analysis of prospective evidence. Hypertension. 2010; 55(4):1026-1032. [PubMed: 20194301]

72. Delius W, et al. Manoeuvres affecting sympathetic outflow in human skin nerves. Acta Physiol Scand. 1972; 84(2):177-186. [PubMed: 5015185]

73. Yamamoto K, et al. Skin sympathetic nerve activity in Guillain-Barre syndrome: a microneurographic study. J Neurol Neurosurg Psychiatry. 1997; 63(4):537-541. [PubMed: 9343142]

74. Iwase $\mathrm{S}$, et al. Altered response in cutaneous sympathetic outflow to mental and thermal stimuli in primary palmoplantar hyperhidrosis. J Auton Nerv Syst. 1997; 64(2-3):65-73. [PubMed: 9203126]

75. Muller MD, Sauder CL, Ray CA. Mental Stress Elicits Sustained and Reproducible Increases in Skin Sympathetic Nerve Activity. Physiol Rep. 2013; 1(1)

76. Wilkinson DJ, et al. Sympathetic activity in patients with panic disorder at rest, under laboratory mental stress, and during panic attacks. Arch Gen Psychiatry. 1998; 55(6):511-520. [PubMed: 9633669]

77. Lambert E, et al. Single-unit analysis of sympathetic nervous discharges in patients with panic disorder. J Physiol. 2006; 570(Pt 3):637-643. [PubMed: 16308348]

78. Lambert EA, et al. Single-unit muscle sympathetic nervous activity and its relation to cardiac noradrenaline spillover. J Physiol. 2011; 589(Pt 10):2597-2605. [PubMed: 21486790]

79. Ehringer H, Hornykiewicz O. [Distribution of noradrenaline and dopamine (3-hydroxytyramine) in the human brain and their behavior in diseases of the extrapyramidal system.]. Wien. Klin. Wochenschr. 1960; 38:1236-1239.

80. Hornykiewicz O. Biochemical aspects of Parkinson's disease. Neurology. 1998; 51(2 Suppl 2):S2S9.

81. Schultz W. Behavioral dopamine signals. Trends Neurosci. 2007; 30(5):203-210. [PubMed: 17400301]

82. Schultz W. Behavioral theories and the neurophysiology of reward. Annu. Rev. Psychol. 2006; 57:87-115. [PubMed: 16318590]

83. Volkow ND, et al. Addiction circuitry in the human brain. Annu. Rev. Pharmacol. Toxicol. 2012; 52:321-336. [PubMed: 21961707]

84. Blier P. Neurotransmitter targeting in the treatment of depression. J. Clin. Psychiatry. 2013; 74(Suppl 2):19-24. [PubMed: 24191974]

85. Goldstein DS, et al. Is there a third peripheral catecholaminergic system? Endogenous dopamine as an autocrine/paracrine substance derived from plasma DOPA and inactivated by conjugation. Hypertens. Res. 1995; 18(Suppl 1):S93-S99. [PubMed: 8529081]

86. Wolfovitz E, et al. Derivation of urinary dopamine from plasma dihydroxyphenylalanine in humans. Clin. Sci. 1993; 84:549-557. [PubMed: 8504632]

87. Ferreira A, et al. The renal dopaminergic system, neurohumoral activation, and sodium handling in heart failure. Am. Heart J. 2002; 143(3):391-397. [PubMed: 11868042]

88. Eisenhofer G, et al. Substantial production of dopamine in the human gastrointestinal tract. J. Clin. Endocrinol. Metab. 1997; 82(11):3864-3871. [PubMed: 9360553] 
89. Goldstein DS, Holmes C. Neuronal source of plasma dopamine. Clin. Chem. 2008; 54(11):18641871. [PubMed: 18801936]

90. Man in't Veld AJ, et al. Congenital dopamine-beta-hydroxylase deficiency. Lancet. 1987; 1:183188. [PubMed: 2880016]

91. Biaggioni I, Robertson D. Endogenous restoration of noradrenaline by precursor therapy in dopamine-beta-hydroxylase deficiency. Lancet. 1987; 2(8569):1170-1172. [PubMed: 2890806]

92. Biederman J, Spencer T. Attention-deficit/hyperactivity disorder (ADHD) as a noradrenergic disorder. Biol. Psychiatry. 1999; 46(9):1234-1242. [PubMed: 10560028]

93. Southwick SM, et al. Role of norepinephrine in the pathophysiology and treatment of posttraumatic stress disorder. Biol. Psychiatry. 1999; 46(9):1192-1204. [PubMed: 10560025]

94. Geracioti TD Jr, et al. Effects of trauma-related audiovisual stimulation on cerebrospinal fluid norepinephrine and corticotropin-releasing hormone concentrations in post-traumatic stress disorder. Psychoneuroendocrinology. 2008; 33(4):416-424. [PubMed: 18295412]

95. Pietrzak RH, et al. Association of posttraumatic stress disorder with reduced in vivo norepinephrine transporter availability in the locus coeruleus. JAMA Psychiatry. 2013; 70(11): 1199-1205. [PubMed: 24048210]

96. Krystal JH, Neumeister A. Noradrenergic and serotonergic mechanisms in the neurobiology of posttraumatic stress disorder and resilience. Brain Res. 2009; 1293:13-23. [PubMed: 19332037]

97. Taylor BK, Roderick RE, Basbaum AI. Brainstem noradrenergic control of nociception is abnormal in the spontaneously hypertensive rat. Neurosci. Lett. 2000; 291(3):139-142. [PubMed: 10984626]

98. Howe JR, Zieglgansberger W. Spinal peptidergic and catecholaminergic systems and nociception. Neurosurgery. 1984; 15(6):904-912. [PubMed: 6083505]

99. Proudfit HK. Pharmacologic evidence for the modulation of nociception by noradrenergic neurons. Prog. Brain Res. 1988; 77:357-370. [PubMed: 3064177]

100. Goddard AW, et al. Current perspectives of the roles of the central norepinephrine system in anxiety and depression. Depress. Anxiety. 2010; 27(4):339-350. [PubMed: 19960531]

101. Cannon WB, de la Paz D. Emotional stimulation of adrenal gland secretion. Am. J. Physiol. 1911; 28:64-70.

102. Goldstein DS, et al. A test of the "epinephrine hypothesis" in humans. Hypertension. 1999; 33(1): 36-43. [PubMed: 9931079]

103. Best JD, Halter JB. Release and clearance rates of epinephrine in man: importance of arterial measurements. J. Clin. Endocrinol. Metab. 1982; 55(2):263-268. [PubMed: 7085853]

104. Goldstein DS, et al. Plasma norepinephrine pharmacokinetics during mental challenge. Psychosom. Med. 1987; 49:591-605. [PubMed: 2827219]

105. Kvetnansky R, Sabban EL, Palkovits M. Catecholaminergic systems in stress: structural and molecular genetic approaches. Physiol. Rev. 2009; 89(2):535-606. [PubMed: 19342614]

106. Kvetnansky R, et al. Effect of novel stressors on tyrosine hydroxylase gene expression in the adrenal medulla of repeatedly immobilized rats. Neurochem. Res. 2003; 28(3-4):625-630. [PubMed: 12675153]

107. Abercrombie ED. Enhanced tyrosine hydroxylation in hippocampus of chronically stressed rats upon exposure to a novel stressor. J. Neurochem. 1992; 58:276-281. [PubMed: 1345767]

108. Karlamangla AS, Singer BH, Seeman TE. Reduction in allostatic load in older adults is associated with lower all-cause mortality risk: MacArthur studies of successful aging. Psychosom. Med. 2006; 68(3):500-507. [PubMed: 16738085]

109. Cannon WB, Britton SW. The influence of motion and emotion on medulliadrenal secretion. Am. J. Physiol. 1927; 79:433-465.

110. Cannon WB. The emergency function of the adrenal medulla in pain and in the major emotions. Am. J. Physiol. 1914; 33:356-372.

111. Cannon WB. The interrelation of emotions as suggested by recent physiological researches. Am. J. Psychol. 1914; 25:256-282.

112. Dale HH, Feldberg W. The chemical transmission of secretory impulses to the sweat glands of the cat. J. Physiol. 1934; 82(1):121-128. [PubMed: 16994562] 
113. Battelli MG. Dosage colorimetrique de la substance active des capsules surrenales. Compt. Rend. Soc. Biol. 1902; 54:571-573.

114. von Euler US, Hamberg U. Colorimetric determination of noradrenaline and adrenaline. Acta Physiol. Scand. 1949; 19:74-84.

115. von Euler US. The development and applications of the trihydroxyindole method for catechols. Pharmacol. Rev. 1959; 11:262-268. [PubMed: 13667403]

116. Weil-Malherbe H. The fluorimetric estimation of adrenaline, noradrenaline and hydroxytyramine in urine. Biochem. J. 1956; 63:4P.

117. Weil-Malherbe $\mathrm{H}$. The fluorimetric estimation of catechol compounds by the ethylenediamine condensation method. Pharmacol. Rev. 1959; 11:277-288.

118. Weil-Malherbe H, Bone AD. The estimation of catecholamines in urine by a chemical method. J. Clin. Pathol. 1957; 10(2):138-147. [PubMed: 13428871]

119. Weil-Malherbe H, Bone AD. The fluorimetric estimation of adrenaline and noradrenaline in plasma. Biochem. J. 1957; 67(1):65-72. [PubMed: 13471512]

120. Mason JW, et al. Concurrent plasma epinephrine, norepinephrine and 17-hydroxycorticosteroid levels during conditioned emotional disturbances in monkeys. Psychosom. Med. 1961; 23:344353. [PubMed: 13767821]

121. Mason JW, Brady JV, Tolson WW. Behavioral adaptations and endocrine activity. Psychoendocrine differentiation of emotional states. Res. Publ. Assoc. Res. Nerv. Ment. Dis. 1966; 43:227-250. [PubMed: 4958079]

122. Mason JW, et al. Urinary epinephrine and norepinephrine responses to 72-hr. avoidance sessions in the monkey. Psychosom. Med. 1968; 30(5 Suppl):654-665.

123. Frazier TW, Weil-Malherbe H, Lipscomb HS. Psychophysiology of conditioned emotional distrubances in humans. Psychophysiology. 1969; 5(5):478-503. [PubMed: 5768008]

124. Ax AF. The physiological differentiation between fear and anger in humans. Psychosom. Med. 1953; 15:433-442. [PubMed: 13100546]

125. Funkenstein DH. Nor-epinephrine-like and epinephrine-like substances in relation to human behavior. J. Mental. Dis. 1956; 124:58-68.

126. Elmadjian F, Hope JM, Lamson ET. Excretion of epinephrine and norepinephrine in various emotional states. J. Clin. Endocrinol. Metab. 1965; 17:608-620.

127. Esler M, et al. Measurement of total and organ-specific norepinephrine kinetics in humans. Am. J. Physiol. 1984; 247:E21-E28. [PubMed: 6742187]

128. Esler M, et al. Contribution of individual organs to total noradrenaline release in humans. Acta Physiol. Scand. 1984; 527(Suppl):11-16.

129. Esler M, et al. Overflow of catecholamine neurotransmitters to the circulation: Source, fate, and functions. Physiol. Rev. 1990; 70:963-985. [PubMed: 1977182]

130. Aneman A, et al. Sympathetic discharge to mesenteric organs and the liver. Evidence for substantial mesenteric organ norepinephrine spillover. J. Clin. Invest. 1996; 97:1640-1646. [PubMed: 8601629]

131. Eisenhofer G, et al. Sympathetic nervous function in human heart as assessed by cardiac spillovers of dihydroxyphenylglycol and norepinephrine. Circulation. 1992; 85:1775-1785. [PubMed: 1572033]

132. Kopin IJ, et al. Different relationships of spillover to release of norepinephrine in human heart, kidneys, and forearm. Am. J. Physiol. 1998; 275:R165-R173. [PubMed: 9688975]

133. Krahenbuhl GS, et al. Biogenic amine/metabolite response during in-flight emergencies. Aviat. Space Environ. Med. 1985; 56(6):576-580. [PubMed: 2409957]

134. Goldstein DS, Kopin IJ. Adrenomedullary, adrenocortical, and sympathoneural responses to stressors: A meta-analysis. Endo. Regul. 2008; 42:111-119.

135. Rea RF, et al. Relation of plasma norepinephrine and sympathetic traffic during hypotension in man. Am. J. Physiol. 1990; 258:R982-R986. [PubMed: 2331039]

136. Lake CR, Ziegler MG, Kopin IJ. Use of plasma norepinephrine for evaluation of sympathetic neuronal function in man. Life Sci. 1976; 18:1315-1325. [PubMed: 933720] 
137. Goldstein DS, Tack C, Li ST. Sympathetic innervation and function in reflex sympathetic dystrophy. Ann. Neurol. 2000; 48(1):49-59. [PubMed: 10894215]

138. Patel JN, et al. Norepinephrine spillover from human adipose tissue before and after a 72-hour fast. J. Clin. Endocrinol. Metab. 2002; 87(7):3373-3377. [PubMed: 12107252]

139. Goldstein DS, et al. Sources and physiological significance of plasma dopamine sulfate. J. Clin. Endocrinol. Metab. 1999; 84(7):2523-2531. [PubMed: 10404831]

140. Elman I, et al. Inverse relationship between plasma epinephrine and testosterone levels during acute glucoprivation in healthy men. Life Sci. 2001; 68(16):1889-1898. [PubMed: 11292066]

141. Goldstein DS, et al. Plasma levels of catecholamines and corticotrophin during acute glucopenia induced by 2-deoxy-D-glucose in normal man. Clin. Auton. Res. 1992; 2:359-366. [PubMed: 1337845]

142. Lake CR, et al. Hydrochlorothiazide-induced sympathetic hyperactivity in hypertensive patients. Clin. Pharmacol. Ther. 1979; 26(4):428-432. [PubMed: 487689]

143. Breier A, et al. Effects of alprazolam on pituitary-adrenal and catecholaminergic responses to metabolic stress in humans. Biol. Psychiatry. 1992; 32(10):880-890. [PubMed: 1334713]

144. Akashi YJ, et al. Takotsubo cardiomyopathy: A new form of acute, reversible heart failure. Circulation. 2008; 118:2754-2762. [PubMed: 19106400]

145. Akashi YJ, et al. The clinical features of takotsubo cardiomyopathy. Q.J.M. 2003; 96(8):563-573.

146. Wittstein IS, et al. Neurohumoral features of myocardial stunning due to sudden emotional stress. N. Engl. J. Med. 2005; 352:539-548. [PubMed: 15703419]

147. Goldstein DS, et al. Plasma dihydroxyphenylglycol and the intraneuronal disposition of norepinephrine in humans. J. Clin. Invest. 1988; 81:213-220. [PubMed: 3335637]

148. Akashi YJ, et al. 123I-MIBG myocardial scintigraphy in patients with "takotsubo" cardiomyopathy. J. Nucl. Med. 2004; 45(7):1121-1127. [PubMed: 15235057]

149. Verschure DO, et al. Tako-tsubo cardiomyopathy: How to understand possible pathophysiological mechanism and the role of I-MIBG imaging. J. Nucl. Cardiol. 2014

150. Pessoa PM, et al. Assessment of takotsubo (ampulla) cardiomyopathy using iodine-123 metaiodobenzylguanidine scintigraphy. Acta Radiol. 2006; 47(10):1029-1035. [PubMed: 17135004]

151. Tagawa M, et al. Transient left ventricular apical ballooning developing after the Central Niigata Prefecture Earthquake: two case reports. J. Cardiol. 2006; 48(3):153-158. [PubMed: 17007240]

152. Eldadah BA, et al. Cardiac uptake-1 inhibition by high circulating norepinephrine levels in patients with pheochromocytoma. Hypertension. 2004; 43(6):1227-1232. [PubMed: 15078865]

153. Kume T, et al. Local release of catecholamines from the hearts of patients with tako-tsubo-like left ventricular dysfunction. Circ. J. 2008; 72(1):106-108. [PubMed: 18159109]

154. Lyon AR, et al. Stress (Takotsubo) cardiomyopathy--a novel pathophysiological hypothesis to explain catecholamine-induced acute myocardial stunning. Nat. Clin. Pract. Cardiovasc. Med. 2008; 5(1):22-29. [PubMed: 18094670]

155. Paur H, et al. High levels of circulating epinephrine trigger apical cardiodepression in a beta2adrenergic receptor/Gi-dependent manner: a new model of Takotsubo cardiomyopathy. Circulation. 2012; 126(6):697-706. [PubMed: 22732314]

156. Verrier RL, Hagestad EL, Lown B. Delayed myocardial ischemia induced by anger. Circulation. 1987; 75:249-254. [PubMed: 3791606]

157. Corbalan K, Verrier R, Lown B. Psychological stress and ventricular arrhythmias during myocardial infarction in the conscious dog. Am. J. Cardiol. 1974; 34:692-696. [PubMed: 4472806]

158. DeSilva RA, Verrier RL, Lown B. The effects of psychological stress and vagal stimulation with morphine on vulnerability to ventricular fibrillation (VF) in the conscious dog. Am. Heart J. 1978; 95:197-203. [PubMed: 74946]

159. Lown B, Verrier RL. Neural activity and ventricular fibrillation. N. Engl. J. Med. 1976; 294:1165-1170. [PubMed: 57572] 
160. Lombardi F, Verrier RL, Lown B. Relationship between sympathetic neural activity, coronary dynamics and vulnerability to ventricular fibrillation during myocardial ischemia and reperfusion. Am. Heart J. 1983; 105:958-965. [PubMed: 6858844]

161. Lampert R, et al. Destabilizing effects of mental stress on ventricular arrhythmias in patients with implantable cardioverter-defibrillators. Circulation. 2000; 101(2):158-164. [PubMed: 10637203]

162. Ylanen K, et al. Catecholaminergic polymorphic ventricular tachycardia. Eur J Pediatr. 2010; 169(5):535-542. [PubMed: 20143088]

163. Gyorke S. Molecular basis of catecholaminergic polymorphic ventricular tachycardia. Heart Rhythm. 2009; 6(1):123-129. [PubMed: 19121813]

164. Heiner JD, Bullard-Berent JH, Inbar S. Deadly proposal: a case of catecholaminergic polymorphic ventricular tachycardia. Pediatr. Emerg. Care. 2011; 27(11):1065-1068. [PubMed: 22068070]

165. Hayashi M, et al. Incidence and risk factors of arrhythmic events in catecholaminergic polymorphic ventricular tachycardia. Circulation. 2009; 119(18):2426-2434. [PubMed: 19398665]

166. Hofferberth SC, et al. Left thoracoscopic sympathectomy for cardiac denervation in patients with life-threatening ventricular arrhythmias. J. Thorac. Cardiovasc. Surg. 2014; 147(1):404-409. [PubMed: 24268954]

167. Schneider HE, et al. Left cardiac sympathetic denervation for the management of life-threatening ventricular tachyarrhythmias in young patients with catecholaminergic polymorphic ventricular tachycardia and long QT syndrome. Clin. Res. Cardiol. 2013; 102(1):33-42. [PubMed: 22821214]

168. Wilde AA, et al. Left cardiac sympathetic denervation for catecholaminergic polymorphic ventricular tachycardia. N. Engl. J. Med. 2008; 358(19):2024-2029. [PubMed: 18463378]

169. Marjamaa A, et al. Intravenous epinephrine infusion test in diagnosis of catecholaminergic polymorphic ventricular tachycardia. J. Cardiovasc. Electrophysiol. 2012; 23(2):194-199. [PubMed: 21954897]

170. Lewis T. A lecture on vasovagal syncope and the carotid sinus mechanism. Br. Med. J. 1932; 1:873-876. [PubMed: 20776843]

171. Scherrer U, et al. Vasovagal syncope after infusion of a vasodilator in a heart-transplant recipient. N. Engl. J. Med. 1990; 322:602-604. [PubMed: 2304506]

172. Engel GL. Psychologic distress, vasodepressor (vasovagal) syncope, and sudden death. Ann Int Med. 1978; 89:403-412. [PubMed: 99068]

173. Goldstein DS, et al. Circulatory control mechanisms in vasodepressor syncope. Am. Heart J. 1982; 104:1071-1075. [PubMed: 7136999]

174. Abboud FM. Neurocardiogenic syncope. N. Engl. J. Med. 1993; 328:1117-1120. [PubMed: 8455671]

175. Fitzpatrick AP, et al. Vasovagal reactions may occur after orthotopic heart transplantation. J. Am. Coll. Cardiol. 1993; 21(5):1132-1137. [PubMed: 8459066]

176. Lightfoot JT, Rowe SA, Fortney SM. Occurrence of presyncope in subjects without ventricular innervation. Clin. Sci. 1993; 85:695-700. [PubMed: 8287661]

177. Morgan-Hughes NJ, et al. Vasovagal reactions after heart transplantation. J. Am. Coll. Cardiol. 1993; 22(7):2059.

178. Dickinson CJ. Fainting precipitated by collapse-firing of venous baroreceptors. Lancet. 1993; 342:970-972. [PubMed: 8105220]

179. Schroeder C, et al. Physiological phenomenology of neurally-mediated syncope with management implications. PloS one. 2011; 6(10):e26489. [PubMed: 22046292]

180. Wallin BG, Sundlof G. Sympathetic outflow to muscles during vasovagal syncope. J. Autonom. Nerv. Sys. 1982; 6:287-291.

181. Ellenbogen KA, et al. Neural monitoring of vasovagal syncope. Pacing Clin. Electrophysiol. 1997; 20(3 Pt 2):788-794. [PubMed: 9080511]

182. Mosqueda-Garcia R, et al. Yohimbine in neurally mediated syncope. Pathophysiological implications. J. Clin. Invest. 1998; 102(10):1824-1830. [PubMed: 9819368] 
183. Mosqueda-Garcia R, et al. The elusive pathophysiology of neurally mediated syncope. Circulation. 2000; 102(23):2898-2906. [PubMed: 11104751]

184. Mosqueda-Garcia R, et al. Sympathetic and baroreceptor reflex function in neurally mediated syncope evoked by tilt. J. Clin. Invest. 1997; 99:2736-2744. [PubMed: 9169504]

185. Vaddadi G, et al. Persistence of muscle sympathetic nerve activity during vasovagal syncope. Eur. Heart J. 2010; 31(16):2027-2033. [PubMed: 20304836]

186. Robertson DA, et al. Comparative assessment of stimuli that release neuronal and adrenomedullary catecholamines in man. Circulation. 1979; 59:637-643. [PubMed: 421304]

187. Tatar P, et al. Venous plasma adrenaline response to orthostatic syncope during tilting in healthy men. Clin. Physiol. 1986; 6(3):303-309. [PubMed: 3087688]

188. Jacobs MC, et al. Neurohumoral antecedents of vasodepressor reactions. Eur. J. Clin. Invest. 1995; 25(10):754-761. [PubMed: 8557062]

189. Bhargava B, et al. Changes in circulatory biogenic amines during head-up tilt testing in neurocardiogenic syncope. Indian Heart J. 1996; 48(6):659-662. [PubMed: 9062013]

190. Klingenheben T, et al. Changes in plasma epinephrine concentration and in heart rate during head-up tilt testing in patients with neurocardiogenic syncope: correlation with successful therapy with beta-receptor antagonists. J. Cardiovasc. Electrophysiol. 1996; 7:802-808. [PubMed: 8884509]

191. Kikushima S, et al. Triggering mechanism for neurally mediated syncope induced by head-up tilt test: role of catecholamines and response to propranolol. J. Am. Coll. Cardiol. 1999; 33(2):350357. [PubMed: 9973014]

192. Evans JM, et al. Epinephrine, vasodilation and hemoconcentration in syncopal, healthy men and women. Auton. Neurosci. 2001; 93(1-2):79-90. [PubMed: 11695710]

193. Takase B, et al. Significance of circulatory epinephrine levels in exercise-induced neurally mediated syncope. Clin. Cardiol. 2001; 24(1):15-20. [PubMed: 11195600]

194. Takase B, et al. Different mechanisms of isoproterenol-induced and nitroglycerin-induced syncope during head-up tilt in patients with unexplained syncope: important role of epinephrine in nitroglycerin-induced syncope. J. Cardiovasc. Electrophysiol. 2001; 12(7):791-796. [PubMed: 11469429]

195. Eldadah BA, et al. Failure of propranolol to prevent tilt-evoked systemic vasodilatation, adrenaline release and neurocardiogenic syncope. Clin. Sci. 2006; 111(3):209-216. [PubMed: 16634720]

196. Davies R, et al. The response of arginine vasopressin and plasma renin to postural change in normal man, with observations on syncope. Clin. Sci. Mol. Med. 1976; 51:267-274. [PubMed: 963956]

197. Carroll JF, et al. Hormonal responses in elders experiencing pre-syncopal symptoms during headup tilt before and after exercise training. J. Gerontol. A. Biol. Sci. Med. Sci. 1995; 50(6):M324M329. [PubMed: 7583804]

198. Hasser EM, Bishop VS, Hay M. Interactions between vasopressin and baroreflex control of the sympathetic nervous system. Clin. Exp. Pharmacol. Physiol. 1997; 24(1):102-108. [PubMed: 9043814]

199. Jardine DL, et al. Neurohormonal response to head-up tilt and its role in vasovagal syncope. Am. J. Cardiol. 1997; 79(9):1302-1306. [PubMed: 9164914]

200. Vaddadi G, et al. Recurrent postural vasovagal syncope: sympathetic nervous system phenotypes. Circ. Arrhythm. Electrophysiol. 2011; 4(5):711-718. [PubMed: 21844155]

201. Muscholl E. Peripheral muscarinic control of norepinephrine release in the cardiovascular system. Am. J. Physiol. 1980; 239:H713-H720. [PubMed: 7192494]

202. Jumblatt JE, Hackmiller RC. M2-type muscarinic receptors mediate prejunctional inhibition of norepinephrine release in the human iris-ciliary body. Exp. Eye Res. 1994; 58:175-180. [PubMed: 7512511]

203. Kaufmann H. Neurally mediated syncope: pathogenesis, diagnosis, and treatment. Neurology. 1995; 45(4 Suppl 5):S12-S18.

204. Goldstein DS. Plasma norepinephrine during stress in essential hypertension. Hypertension. 1981; 3:551-556. [PubMed: 7298109] 
205. Goldstein DS. Arterial baroreflex sensitivity, plasma catecholamines, and pressor responsiveness in essential hypertension. Circulation. 1983; 68:234-240. [PubMed: 6407776]

206. Goldstein DS. Plasma catecholamines and essential hypertension. An analytical review. Hypertension. 1983; 5:86-99. [PubMed: 6336721]

207. Goldstein, DS. Stress, Catecholamines, and Cardiovascular Disease. New York: Oxford University Press; 1995.

208. Louis WJ, Doyle AE, Anavekar S. Plasma norepinephrine levels in essential hypertension. N. Engl. J. Med. 1973; 288:599-601. [PubMed: 4686986]

209. Esler M, et al. Mild high-renin essential hypertension: neurogenic human hypertension. N. Engl. J. Med. 1977; 296:405-411. [PubMed: 834210]

210. Goldstein DS, et al. Sympathetic reactivity during a yohimbine challenge test in essential hypertension. Hypertension. 1991; 18(Suppl. III):III-40-III-48. [PubMed: 1657775]

211. Sharabi Y, et al. Sympathoadrenal function in patients with paroxysmal hypertension: pseudopheochromocytoma. J. Hypertens. 2007; 25(11):2286-2295. [PubMed: 17921824]

212. Kjeldsen SE, et al. Evidence of increased peripheral catecholamine release in patients with longstanding, untreated essential hypertension. Scand. J. Clin. Lab. Invest. 1982; 42(3):217-223. [PubMed: 7134805]

213. Flaa A, et al. Sympathetic activity and cardiovascular risk factors in young men in the low, normal, and high blood pressure ranges. Hypertension. 2006; 47(3):396-402. [PubMed: 16446389]

214. Flaa A, et al. Sympathoadrenal stress reactivity is a predictor of future blood pressure: an 18-year follow-up study. Hypertension. 2008; 52(2):336-341. [PubMed: 18574074]

215. Esler M, et al. Total, and organ-specific, noradrenaline plasma kinetics in essential hypertension. Clin. Exper. Hyper. 1984; 6:507-521.

216. Esler M, et al. Mechanism of elevated plasma noradrenaline in the course of essential hypertension. J. Cardiovasc. Pharmacol. 1986; 8(Suppl 5):S39-S43.

217. Esler M, Lambert G, Jennings G. Increased regional sympathetic nervous activity in human hypertension: causes and consequences. J. Hypertension. 1990; 8:S53-S57.

218. Esler M, et al. Biochemical evidence of sympathetic hyperactivity in human hypertension. Hypertension. 1991; 17:III-29-III-35. [PubMed: 2013490]

219. Ferrier C, et al. Evidence for increased noradrenaline release from subcortical brain regions in essential hypertension. J. Hypertens. 1993; 11:1217-1227. [PubMed: 8301103]

220. Esler M. The sympathetic system and hypertension. Am. J. Hypertens. 2000; 13(6 Pt 2):99S105S. [PubMed: 10921528]

221. Esler M, et al. The sympathetic neurobiology of essential hypertension: disparate influences of obesity, stress, and noradrenaline transporter dysfunction? Am. J. Hypertens. 2001; 14:139S146S. [PubMed: 11411749]

222. Parati G, Esler M. The human sympathetic nervous system: its relevance in hypertension and heart failure. Eur. Heart. J. 2012; 33(9):1058-1066. [PubMed: 22507981]

223. Schlaich MP, et al. Renal sympathetic-nerve ablation for uncontrolled hypertension. N. Engl. J. Med. 2009; 361(9):932-934. [PubMed: 19710497]

224. Krum H, et al. Catheter-based renal sympathetic denervation for resistant hypertension: a multicentre safety and proof-of-principle cohort study. Lancet. 2009; 373(9671):1275-1281. [PubMed: 19332353]

225. Ott C, et al. Renal denervation in moderate treatment-resistant hypertension. J. Am. Coll. Cardiol. 2013; 62(20):1880-1886. [PubMed: 23850901]

226. Blanchard EB, et al. Changes in plasma norepinephrine to combat-related stimuli among Vietnam veterans with posttraumatic stress disorder. J. Nerv. Ment. Dis. 1991; 179(6):371-373. [PubMed: 2051153]

227. Kosten TR, et al. Sustained urinary norepinephrine and epinephrine elevation in post-traumatic stress disorder. Psychoneuroendocrinology. 1987; 12:13-20. [PubMed: 3588809]

228. Southwick SM, et al. Neurotransmitter alterations in PTSD: catecholamines and serotonin. Semin. Clin. Neuropsychiatry. 1999; 4(4):242-248. [PubMed: 10553029] 
229. Oquendo MA, et al. Lower cortisol levels in depressed patients with comorbid post-traumatic stress disorder. Neuropsychopharmacology. 2003; 28(3):591-598. [PubMed: 12629542]

230. Videlock EJ, et al. Stress hormones and post-traumatic stress disorder in civilian trauma victims: a longitudinal study. Part II: the adrenergic response. The international journal of neuropsychopharmacology / official scientific journal of the Collegium Internationale Neuropsychopharmacologicum. 2008; 11(3):373-380.

231. Shalev AY, et al. Stress hormones and post-traumatic stress disorder in civilian trauma victims: a longitudinal study. Part I: HPA axis responses. Int. J. Neuropsychopharmacol. 2008; 11(3):365372. [PubMed: 17971262]

232. Hines EA, Brown GE. A standard stimulus for measuring vasomotor reactions: Its application in the study of hypertension. Proc. Staff Meet. Mayo Clinic. 1932; 7:332-335.

233. Hines EA Jr, Brown GE. The cold pressor test for measuring the reactibility of the blood pressure: Data concerning 571 normal and hypertensive subjects. American Heart Journal. 1936; 11(1):19.

234. Barnett PH, et al. Blood pressure and vascular reactivity to the cold pressor test. Restudy of 207 subjects 27 years later. JAMA. 1963; 183:845-848. [PubMed: 13969392]

235. Wood DL, et al. Cold pressor test as a predictor of hypertension. Hypertension. 1984; 6(3):301306. [PubMed: 6735451]

236. Schwartz AR, et al. Toward a causal model of cardiovascular responses to stress and the development of cardiovascular disease. Psychosom Med. 2003; 65(1):22-35. [PubMed: 12554813]

237. Zanstra YJ, Johnston DW. Cardiovascular reactivity in real life settings: measurement, mechanisms and meaning. Biol Psychol. 2011; 86(2):98-105. [PubMed: 20561941]

238. Swain A, Suls J. Reproducibility of blood pressure and heart rate reactivity: a meta-analysis. Psychophysiology. 1996; 33(2):162-174. [PubMed: 8851244]

239. Hassellund SS, et al. Long-term stability of cardiovascular and catecholamine responses to stress tests: An 18-year follow-up study. Hypertension. 2010; 55:131-136. [PubMed: 19948985]

240. Pickering TG, Gerin W. Cardiovascular reactivity in the laboratory and the role of behavioral factors in hypertension: a critical review. Annals of Behavioral Medicine. 1990; 12:3-16.

241. Kamarck TW, et al. Correspondence between laboratory and ambulatory measures of cardiovascular reactivity: a multilevel modeling approach. Psychophysiology. 2003; 40(5):675683. [PubMed: 14696722]

242. Johnston DW, Tuomisto MT, Patching GR. The relationship between cardiac reactivity in the laboratory and in real life. Health Psychol. 2008; 27(1):34-42. [PubMed: 18230011]

243. Collins FS, Tabak LA. Policy: NIH plans to enhance reproducibility. Nature. 2014; 505(7485): 612-613. [PubMed: 24482835]

244. Noll G, et al. Increased activation of sympathetic nervous system and endothelin by mental stress in normotensive offspring of hypertensive parents. Circulation. 1996; 93(5):866-869. [PubMed: 8598076]

245. Spielberger, CD. Manual for the state-trait anxiety inventory. Palo Alto, CA: Consulting Psychologists Press; 1983.

246. Watson D, Clark LA, Tellegen A. Development and validation of brief measures of positive and negative affect: the PANAS scales. J Pers Soc Psychol. 1988; 54(6):1063-1070. [PubMed: 3397865]

247. Vaccaro A, et al. Direct Evidences for Sympathetic Hyperactivity and Baroreflex Impairment in Tako Tsubo Cardiopathy. PLoS ONE. 9(3):e93278. [PubMed: 24667435]

248. Freyschuss U, et al. Cardiovascular and sympathoadrenal responses to mental stress: a study of sensory intake and rejection reactions. Acta Physiol Scand. 1990; 139(1):173-183. [PubMed: 2356747]

249. Matsukawa T, et al. Augmented sympathetic nerve activity in response to stressors in young borderline hypertensive men. Acta Physiol Scand. 1991; 141(2):157-165. [PubMed: 2048404]

250. Elam M, Johansson G, Wallin BG. Do patients with primary fibromyalgia have an altered muscle sympathetic nerve activity? Pain. 1992; 48(3):371-375. [PubMed: 1594259] 
251. Ashino K, et al. Effect of an angiotensin receptor antagonist, TCV-116, on sympathetic nerve activity in patients with essential hypertension. Blood Press Suppl. 1994; 5:122-129. [PubMed: 7889194]

252. Ng AV, et al. Sympathetic neural reactivity to stress does not increase with age in healthy humans. Am J Physiol. 1994; 267(1 Pt 2):H344-H353. [PubMed: 8048600]

253. Jones PP, et al. Gender does not influence sympathetic neural reactivity to stress in healthy humans. Am J Physiol. 1996; 270(1 Pt 2):H350-H357. [PubMed: 8769771]

254. Noll G, et al. Differential effects of captopril and nitrates on muscle sympathetic nerve activity in volunteers. Circulation. 1997; 95(9):2286-2292. [PubMed: 9142006]

255. Middlekauff HR, et al. Impact of acute mental stress on sympathetic nerve activity and regional blood flow in advanced heart failure: implications for 'triggering' adverse cardiac events. Circulation. 1997; 96(6):1835-1842. [PubMed: 9323069]

256. Hausberg M, et al. Sympathetic and vascular effects of short-term passive smoke exposure in healthy nonsmokers. Circulation. 1997; 96(1):282-287. [PubMed: 9236446]

257. Phillips BG, et al. Sympathetic activation by sildenafil. Circulation. 2000; 102(25):3068-3073. [PubMed: 11120696]

258. Kato M, et al. Effects of sleep deprivation on neural circulatory control. Hypertension. 2000; 35(5):1173-1175. [PubMed: 10818083]

259. Schroeder KE, et al. Personality type and neural circulatory control. Hypertension. 2000; 36(5): 830-833. [PubMed: 11082151]

260. Middlekauff HR, Yu JL, Hui K. Acupuncture effects on reflex responses to mental stress in humans. Am J Physiol Regul Integr Comp Physiol. 2001; 280(5):R1462-R1468. [PubMed: 11294769]

261. Wasmund WL, et al. Interactive effects of mental and physical stress on cardiovascular control. J Appl Physiol (1985). 2002; 92(5):1828-1834. [PubMed: 11960930]

262. Middlekauff HR, et al. Acupuncture inhibits sympathetic activation during mental stress in advanced heart failure patients. J Card Fail. 2002; 8(6):399-406. [PubMed: 12528093]

263. Carter JR, Ray CA, Cooke WH. Vestibulosympathetic reflex during mental stress. J Appl Physiol (1985). 2002; 93(4):1260-1264. [PubMed: 12235023]

264. Heusser K, et al. Elevation of sympathetic activity by eprosartan in young male subjects. Am J Hypertens. 2003; 16(8):658-664. [PubMed: 12878372]

265. Dishman RK, et al. Blood pressure and muscle sympathetic nerve activity during cold pressor stress: fitness and gender. Psychophysiology. 2003; 40(3):370-380. [PubMed: 12946111]

266. Kuniyoshi FH, et al. Abnormal neurovascular control during sympathoexcitation in obesity. Obes Res. 2003; 11(11):1411-1419. [PubMed: 14627763]

267. Carter JR, Cooke WH, Ray CA. Forearm neurovascular responses during mental stress and vestibular activation. Am J Physiol Heart Circ Physiol. 2005; 288(2):H904-H907. [PubMed: 15486035]

268. Trombetta IC, et al. Gly16 + Glu27 beta2-adrenoceptor polymorphisms cause increased forearm blood flow responses to mental stress and handgrip in humans. J Appl Physiol (1985). 2005; 98(3):787-794. [PubMed: 15703163]

269. Heindl S, et al. Differential effects of hydrocortisone on sympathetic and hemodynamic responses to sympathoexcitatory manoeuvres in men. Steroids. 2006; 71(3):206-213. [PubMed: 16388832]

270. Tonacio AC, et al. Effects of diet and exercise training on neurovascular control during mental stress in obese women. Braz J Med Biol Res. 2006; 39(1):53-62. [PubMed: 16400464]

271. Kuipers NT, et al. Neurovascular responses to mental stress in the supine and upright postures. J Appl Physiol (1985). 2008; 104(4):1129-1136. [PubMed: 18218909]

272. Durocher JJ, Schwartz CE, Carter JR. Sympathetic neural responses to mental stress during acute simulated microgravity. J Appl Physiol (1985). 2009; 107(2):518-522. [PubMed: 19541737]

273. Scalco AZ, et al. Muscle sympathetic nervous activity in depressed patients before and after treatment with sertraline. J Hypertens. 2009; 27(12):2429-2436. [PubMed: 19684519] 
274. Ray CA, Carter JR. Effects of aerobic exercise training on sympathetic and renal responses to mental stress in humans. Am J Physiol Heart Circ Physiol. 2010; 298(1):H229-H234. [PubMed: 19915172]

275. Klein JC, et al. Combined heat and mental stress alters neurovascular control in humans. J Appl Physiol (1985). 2010; 109(6):1880-1886. [PubMed: 20884834]

276. Schwartz CE, Durocher JJ, Carter JR. Neurovascular responses to mental stress in prehypertensive humans. J Appl Physiol (1985). 2011; 110(1):76-82. [PubMed: 21051574]

277. Durocher JJ, Klein JC, Carter JR. Attenuation of sympathetic baroreflex sensitivity during the onset of acute mental stress in humans. Am J Physiol Heart Circ Physiol. 2011; 300(5):H1788H1793. [PubMed: 21357505]

278. Durocher JJ, et al. Social technology restriction alters state-anxiety but not autonomic activity in humans. Am J Physiol Regul Integr Comp Physiol. 2011; 301(6):R1773-R1778. [PubMed: 21957161]

279. Donadio V, et al. Muscle sympathetic response to arousal predicts neurovascular reactivity during mental stress. J Physiol. 2012; 590(Pt 12):2885-2896. [PubMed: 22526886]

280. Trueb L, et al. Nitric oxide mediates the blood pressure response to mental stress in humans. Swiss Med Wkly. 2012; 142:w13627. [PubMed: 22786663]

281. Hering D, et al. Effects of acute and long-term slow breathing exercise on muscle sympathetic nerve activity in untreated male patients with hypertension. J Hypertens. 2013; 31(4):739-746. [PubMed: 23385649]

282. Hering D, et al. High-normal blood pressure is associated with increased resting sympathetic activity but normal responses to stress tests. Blood Press. 2013; 22(3):183-187. [PubMed: 23356493]

283. Carter JR, et al. Fish oil and neurovascular reactivity to mental stress in humans. Am J Physiol Regul Integr Comp Physiol. 2013; 304(7):R523-R530. [PubMed: 23408034]

284. Dishman RK, et al. Augmented limb blood flow during neurovascular stress in physically fit women. Psychophysiology. 2013; 50(9):831-840. [PubMed: 23802906] 

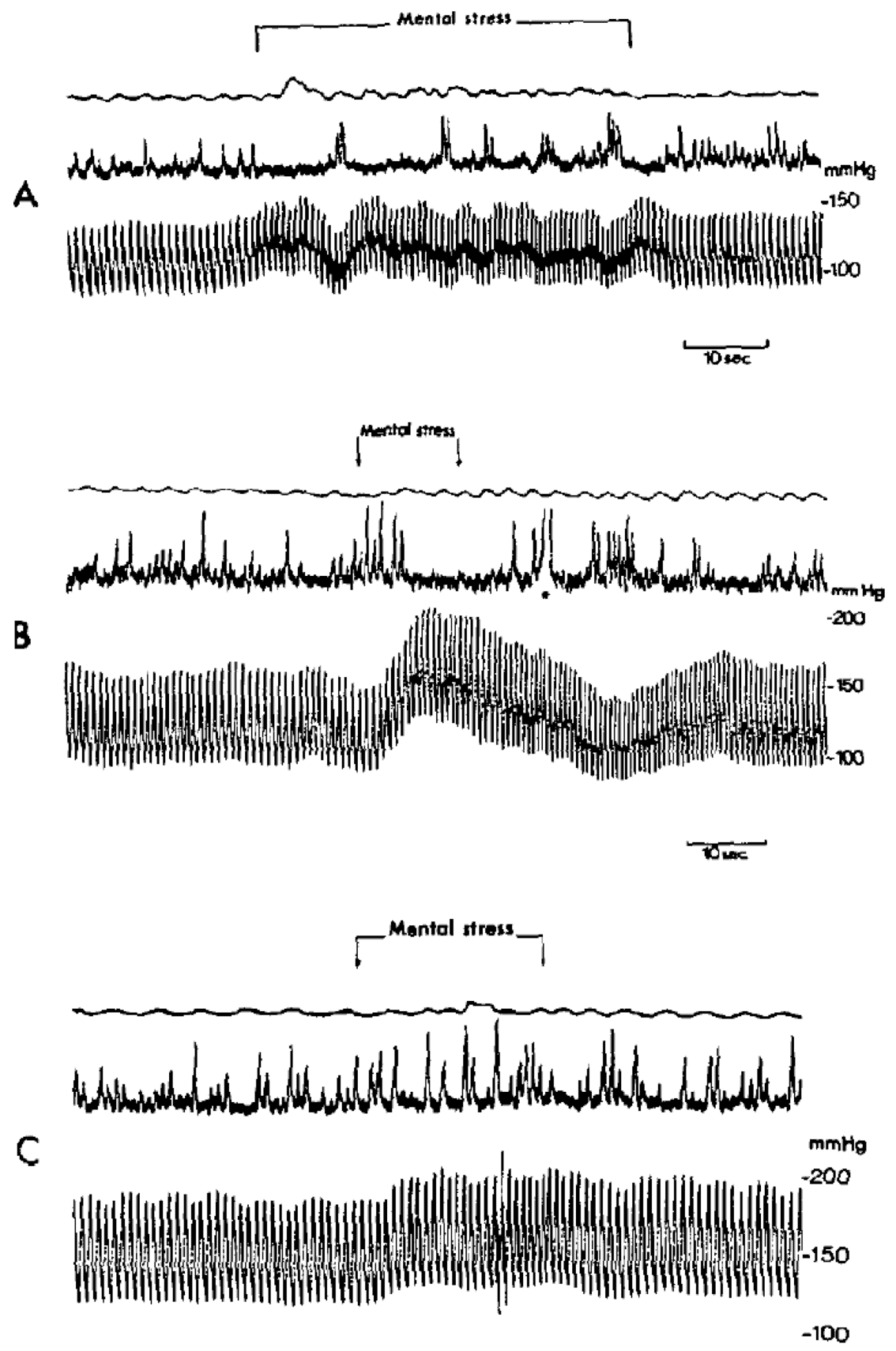

10 sec

Figure 1.

Original recordings of muscle sympathetic nerve activity (MSNA) and beat-to-beat arterial blood pressure during acute, laboratory-based mental stress. Taken with permission from Wallin et al. [55]. 


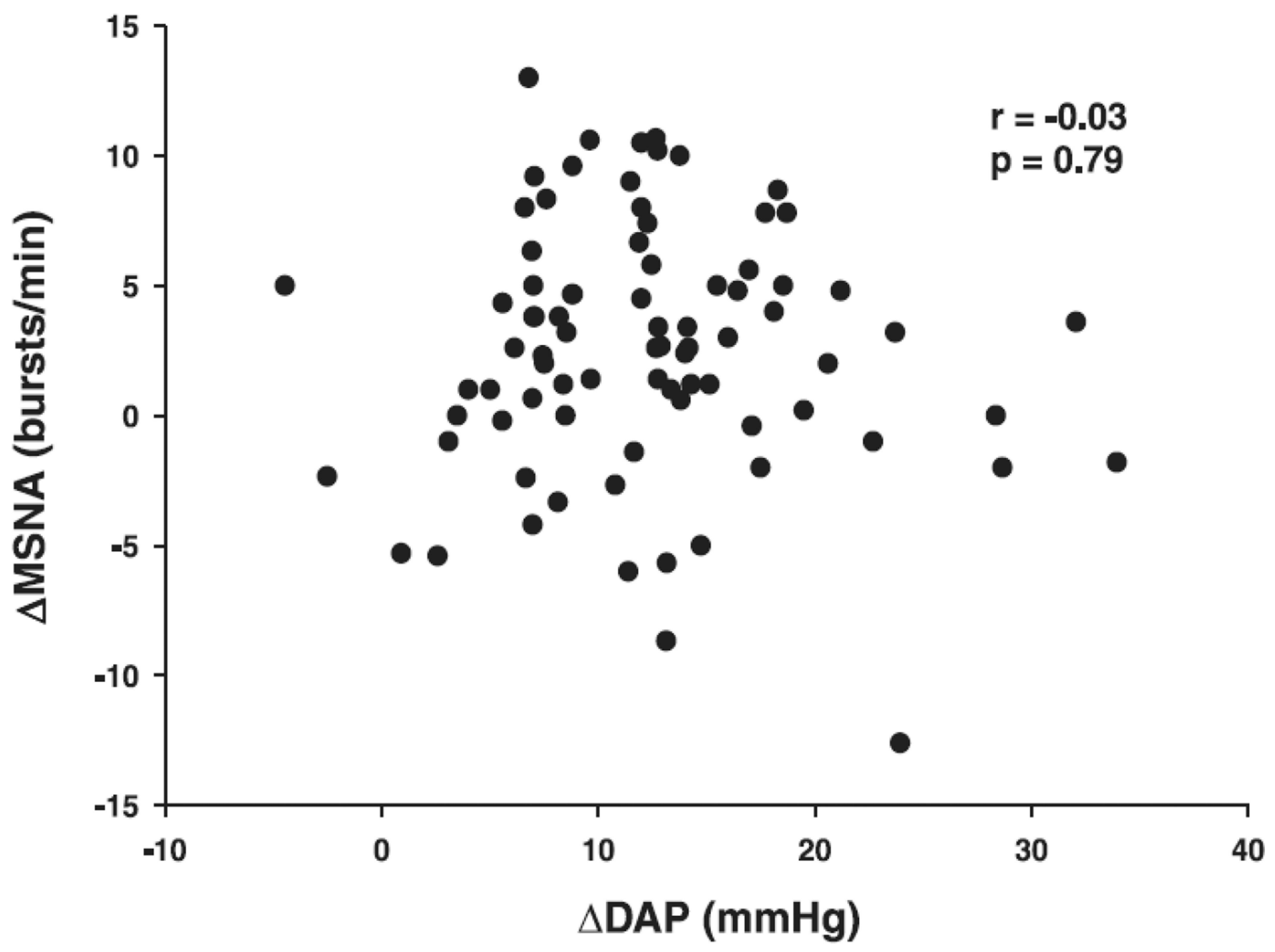

Figure 2.

Muscle sympathetic nerve activity (MSNA) responsiveness to mental stress was not correlated to arterial blood pressure responsiveness; DAP, diastolic arterial pressure. Taken with permission from Carter \& Ray [57]. 

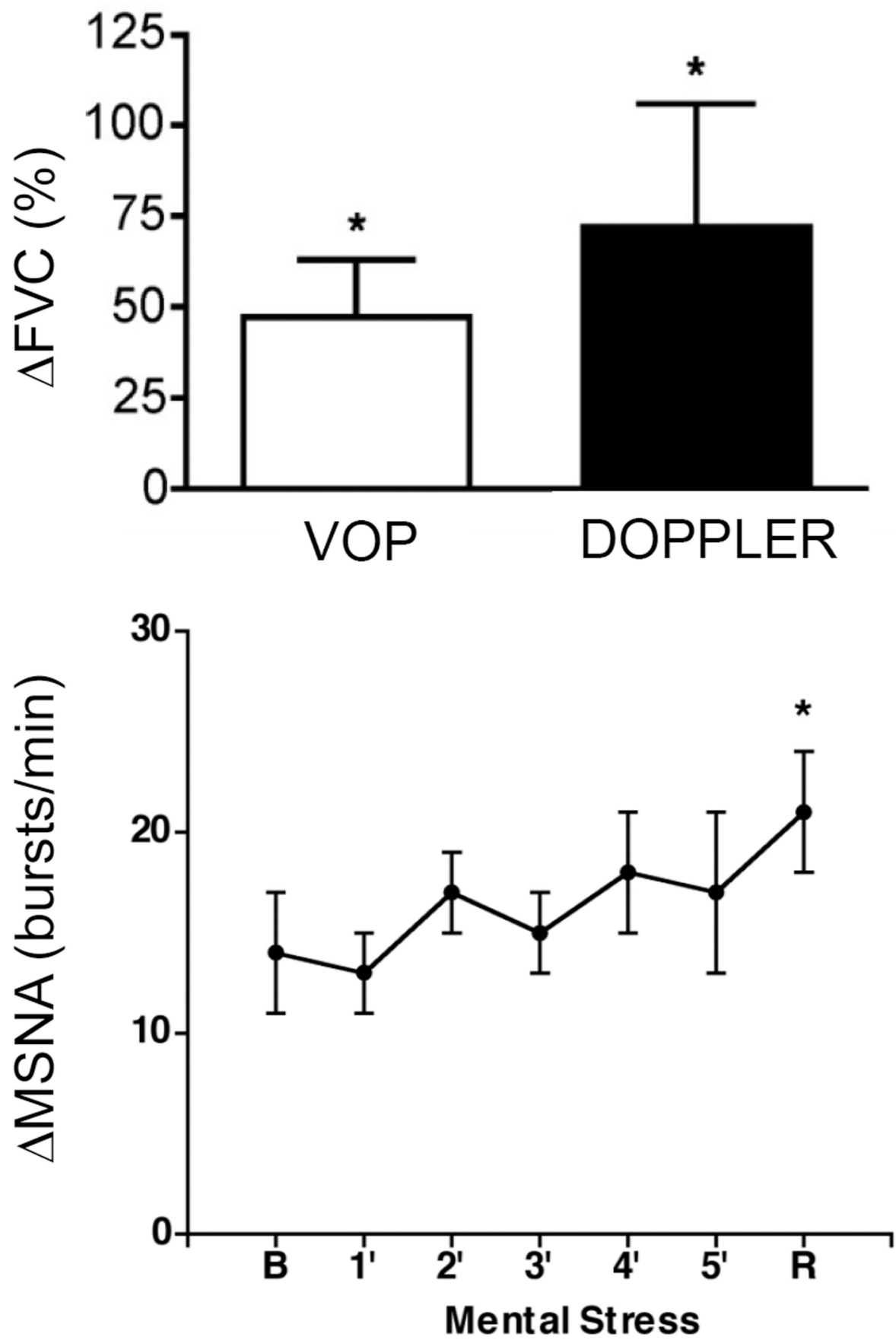

Figure 3.

Mental stress increases forearm vascular conductance (FVC) without any change in forearm muscle sympathetic nerve activity (MSNA); VOP, venous occlusion plethysmography; DOPPLER, Doppler ultrasound technique; B, baseline; R, recovery. Modified with permission from Carter et al. [62]. 
REST
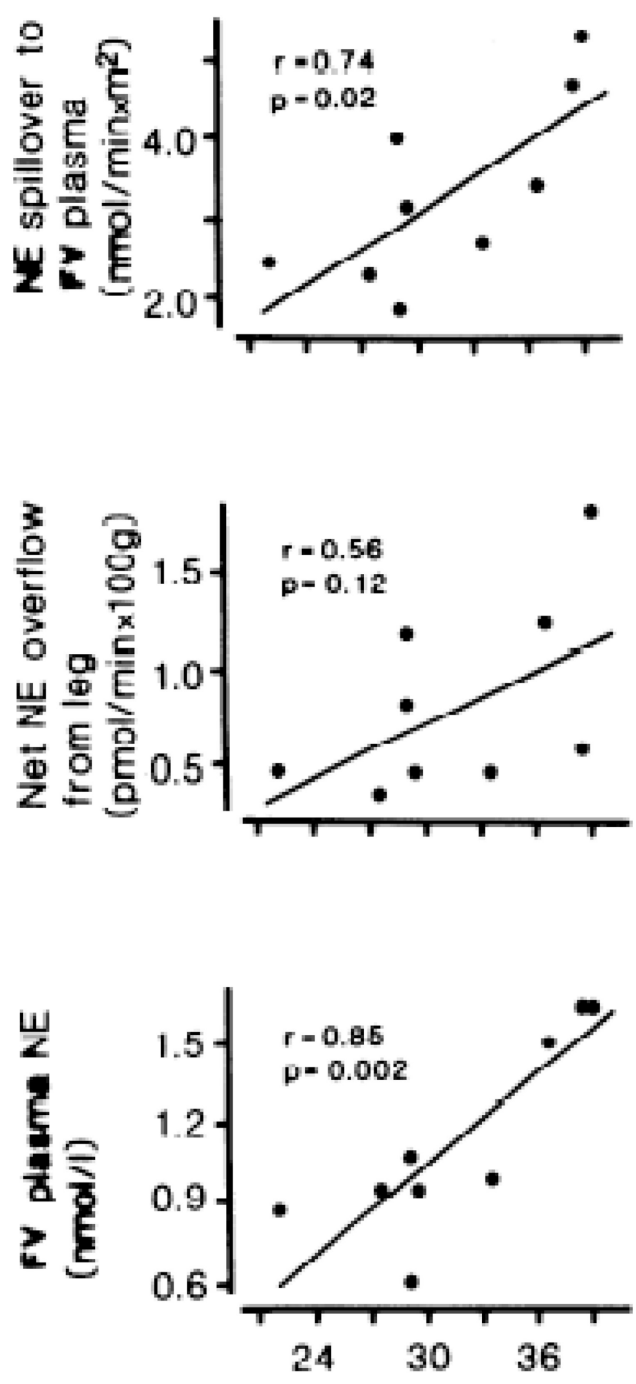

RELAX
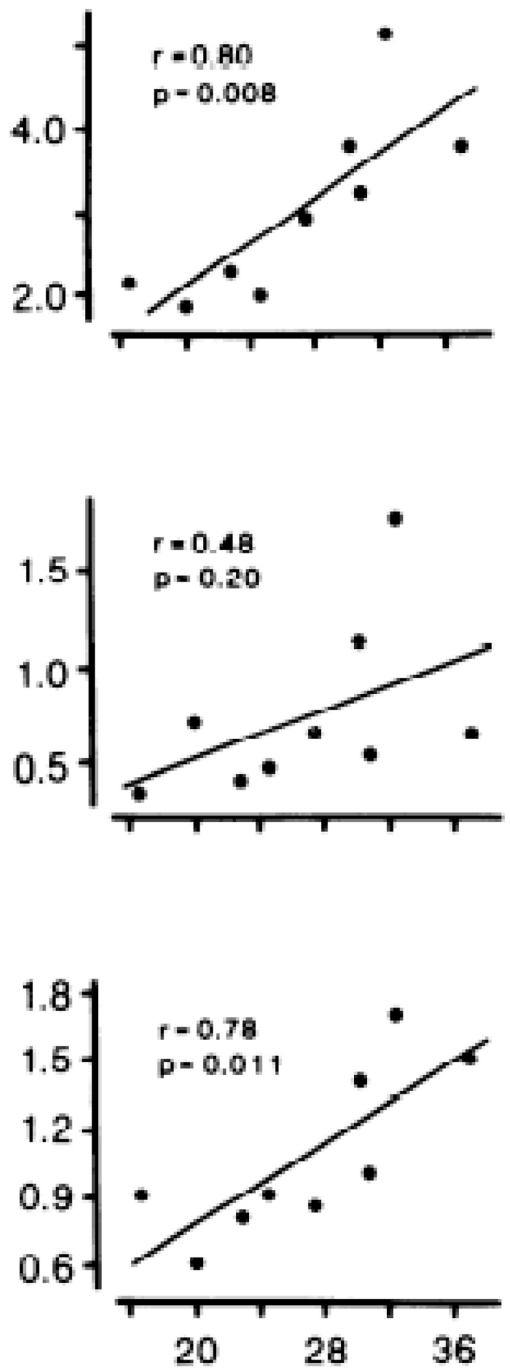

CWT
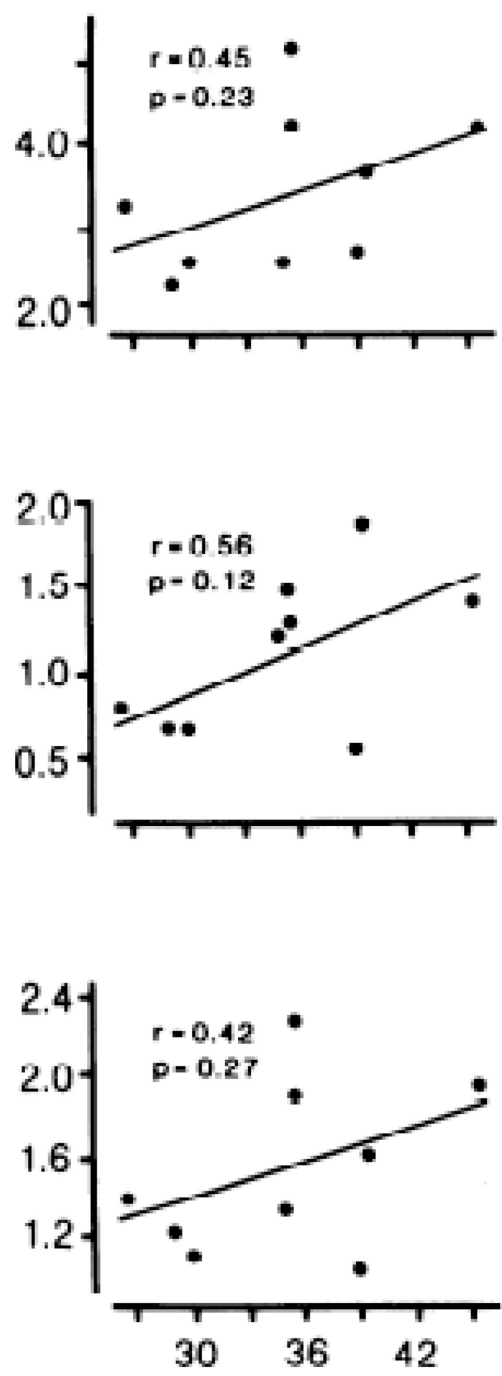

Muscle sympathetic nerve activity (bursts/min)

Figure 4.

Muscle sympathetic nerve activity correlates strongly with femoral venous (FV) plasma norepinephrine (NE) concentrations and spillover at rest, but not during mental stress elicited via Stroop's color word conflict test (CWT). Taken with permission from Hjemdahl et al. [67]. 


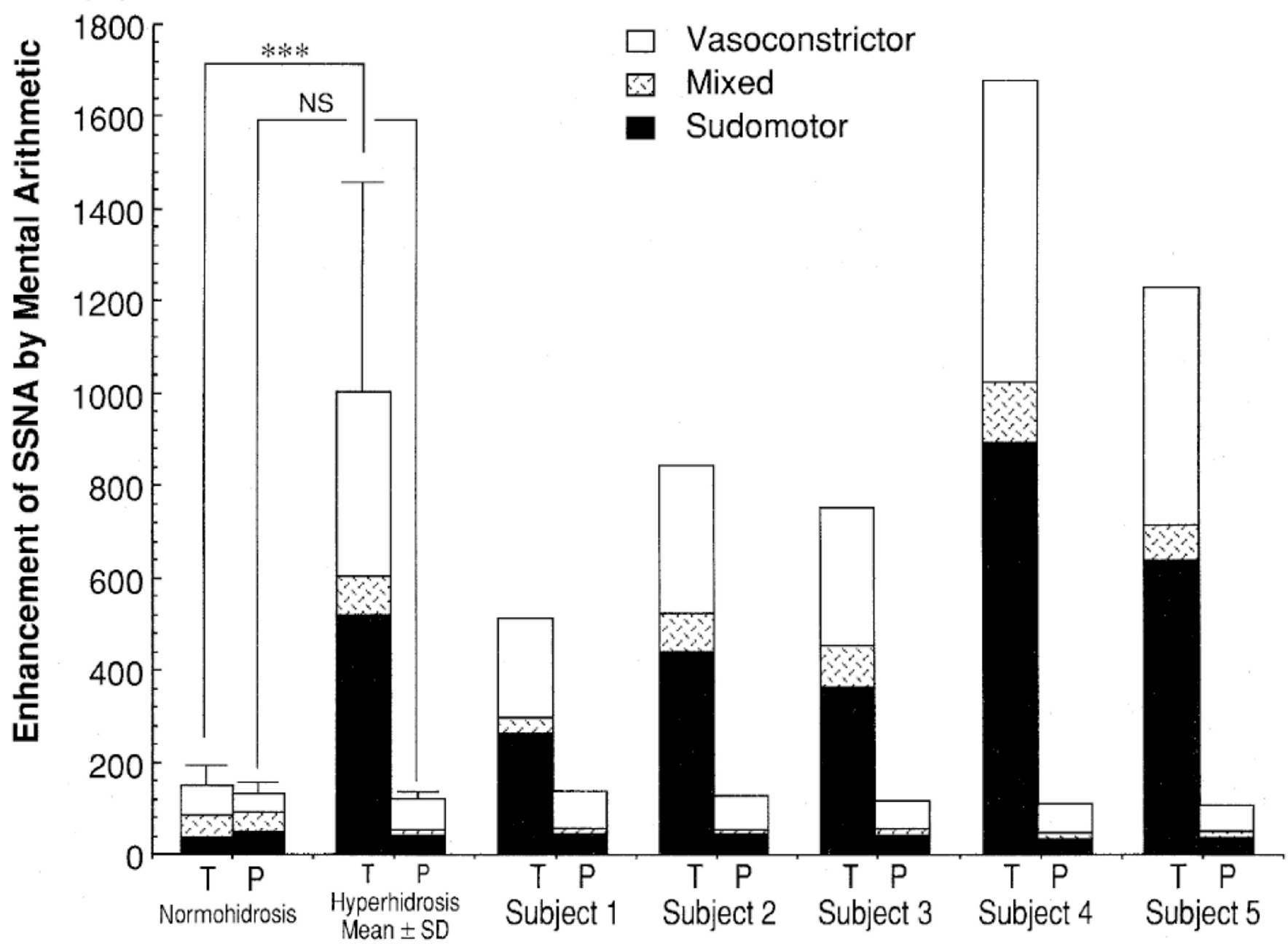

Figure 5.

Skin sympathetic nerve activity (SSNA) responsiveness to mental stress was divergent in the tibial $(\mathrm{T})$ and peroneal $(\mathrm{P})$ nerves of hyperhidrosis patients. Taken with permission from Iwase et al. [74]. 


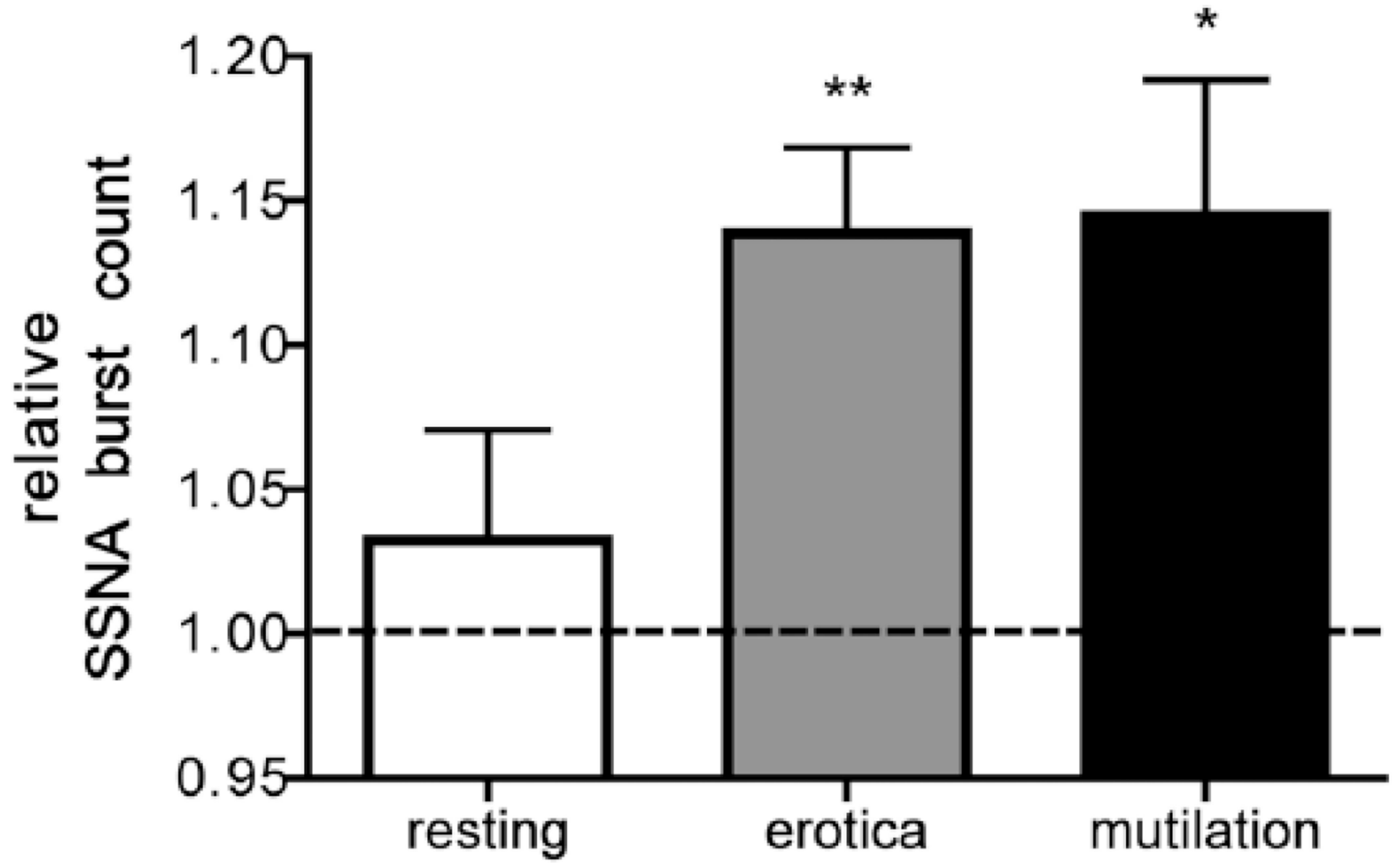

Figure 6.

Skin sympathetic nerve activity (SSNA) responses to emotionally-charged images from the International Affective Picture System (IAPS). Taken with permission from Brown et al. [39]. 

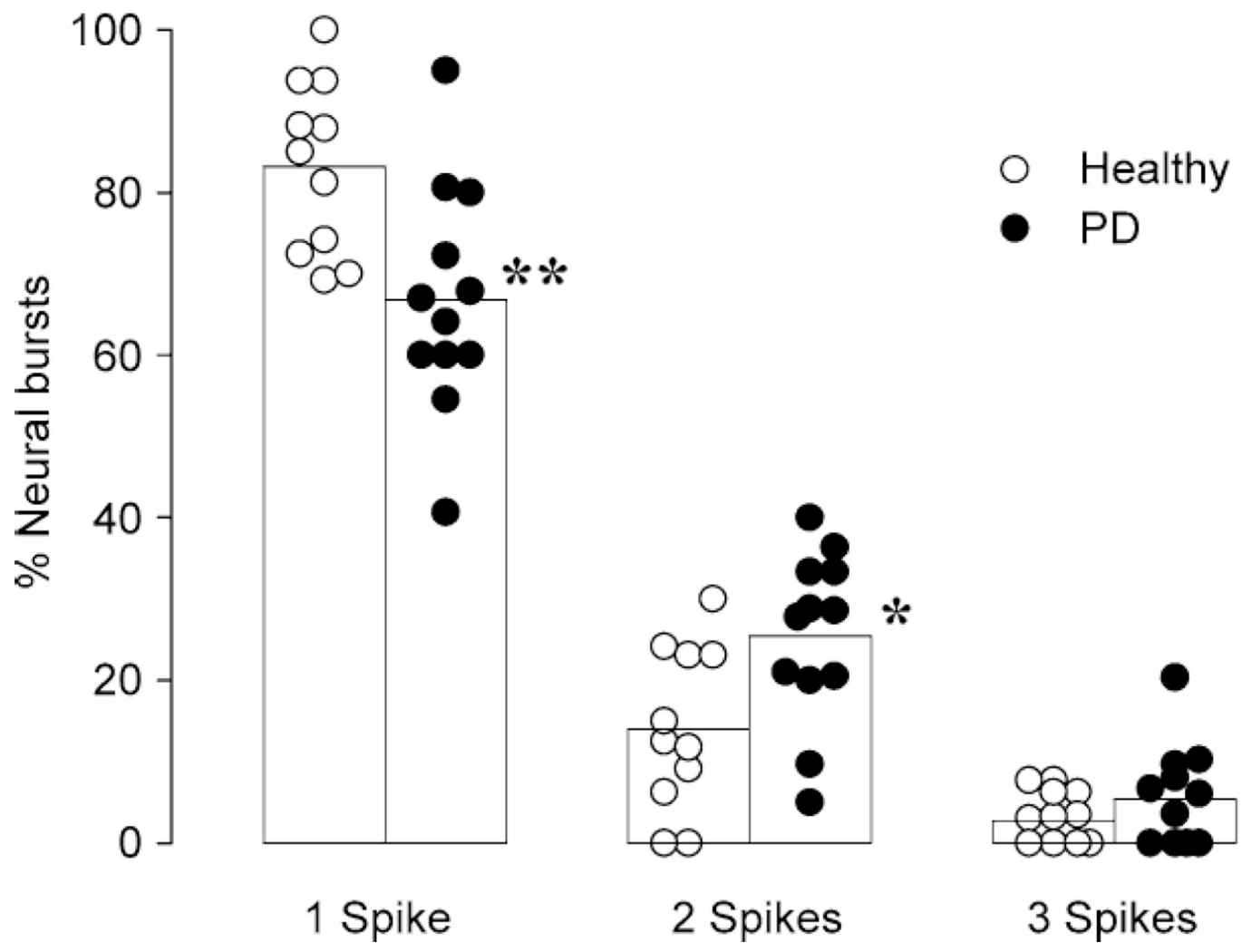

Figure 7.

Panic disorder (PD) patient peripheral sympathetic neurons fire more often in a 'multiple spike' pattern when compared to health controls. Taken with permission from Lambert et al. [77]. 

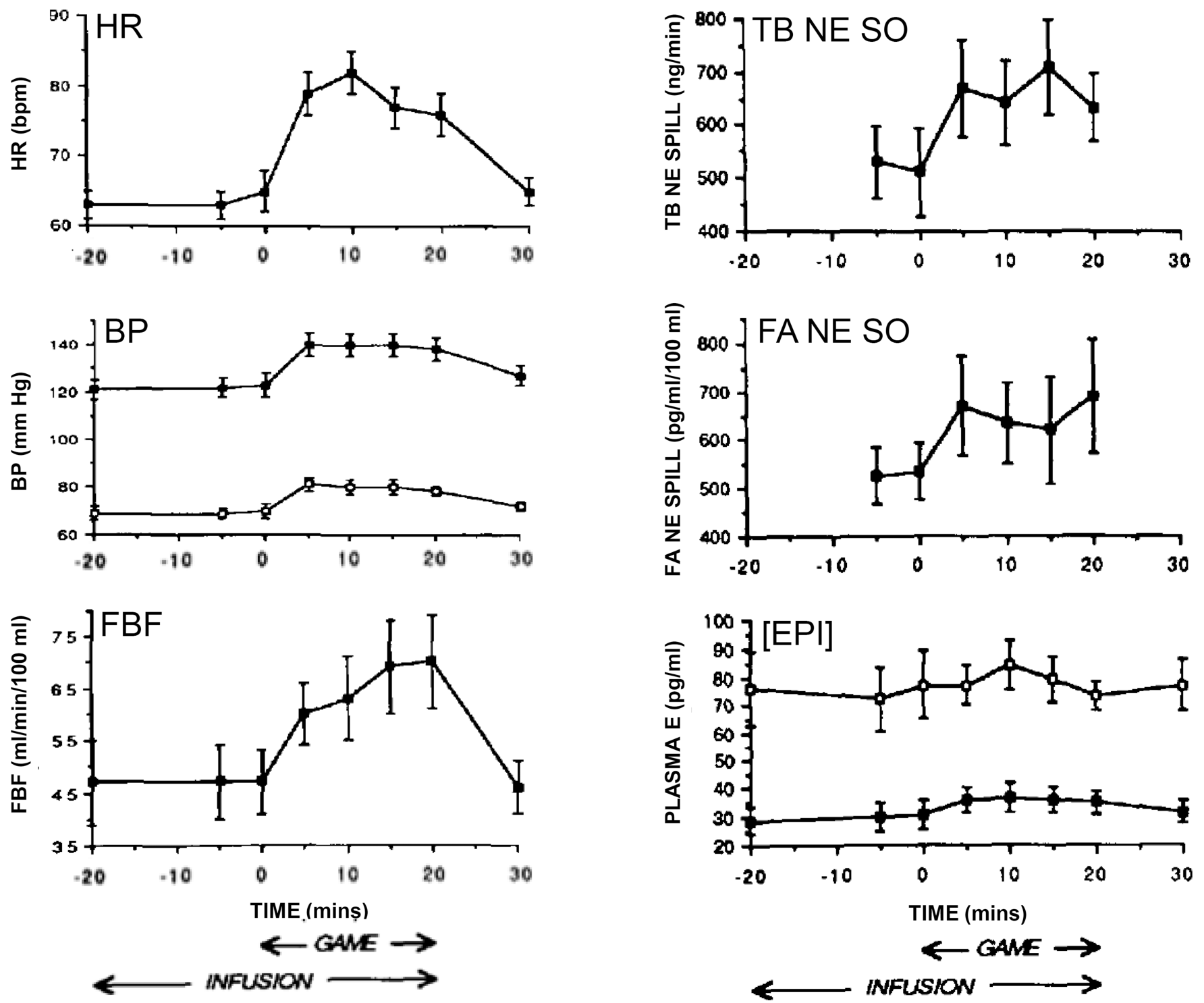

Figure 8. Hemodynamic and catecholamine responses to mental challenge (playing a video game) in healthy humans

There are increases in heart rate (HR), blood pressure (BP), and forearm blood flow (FBF) and concurrent increases in total body and forearm norepinephrine spillover (TB NE SO and FA NE SO), yet arterial and arm venous concentrations of epinephrine ([EPI]) remain unchanged. This pattern exemplifies active attention without distress. 


\section{Adrenols Active Adrenals mactive March 18, 26 April 16,26 \\ Quiet on lap}
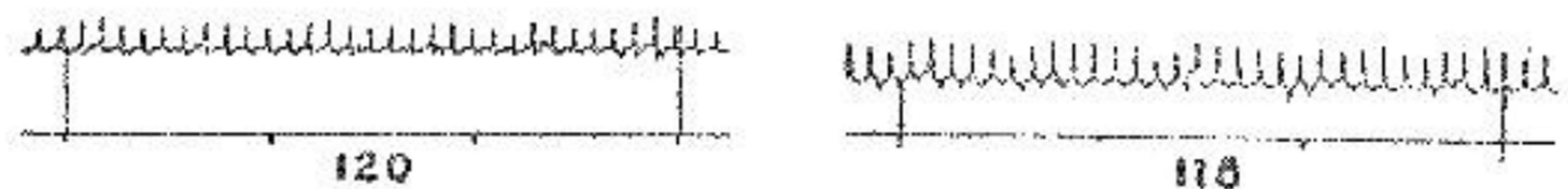

876

After walking

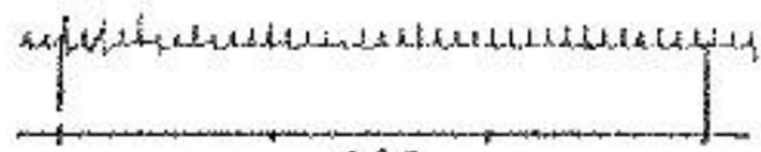

140

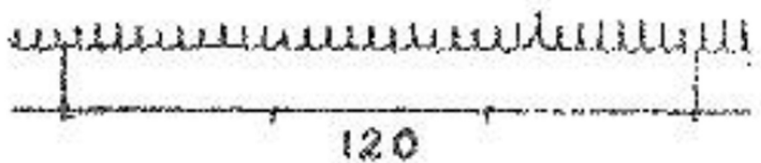

120

\section{After excilement \\ (Doq near)}
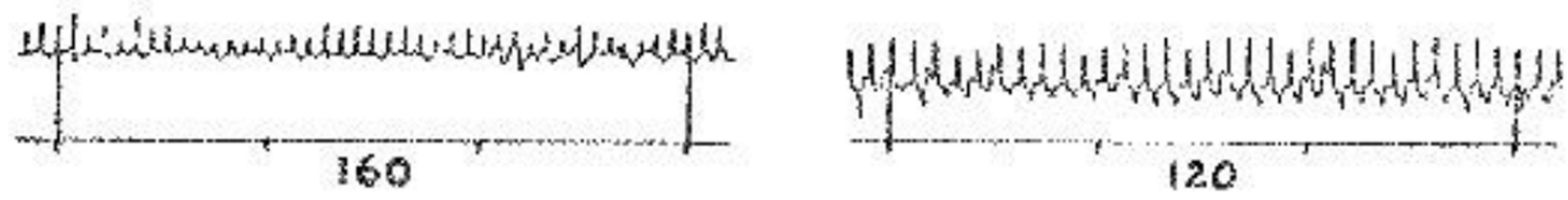

After excitement and siruggie (coped and rencling to dog)
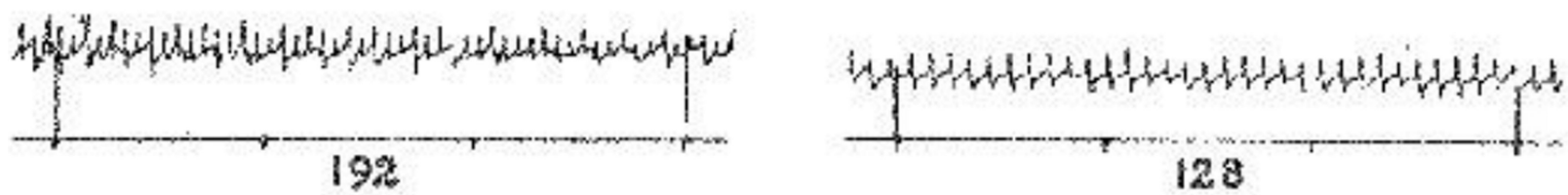

120

Figure 9. Cannon's denervated heart model demonstrating distress-induced adrenal secretion The rate of the denervated heart in a caged cat was recorded upon exposure of the animal to a dog, before and after bilateral adrenal inactivation. The virtual absence of tachycardia in the setting of inactivated adrenals indicated distress-evoked adrenal release of a hormone into the bloodstream. Taken with permission from Cannon [2]. 


\section{Control subjects}

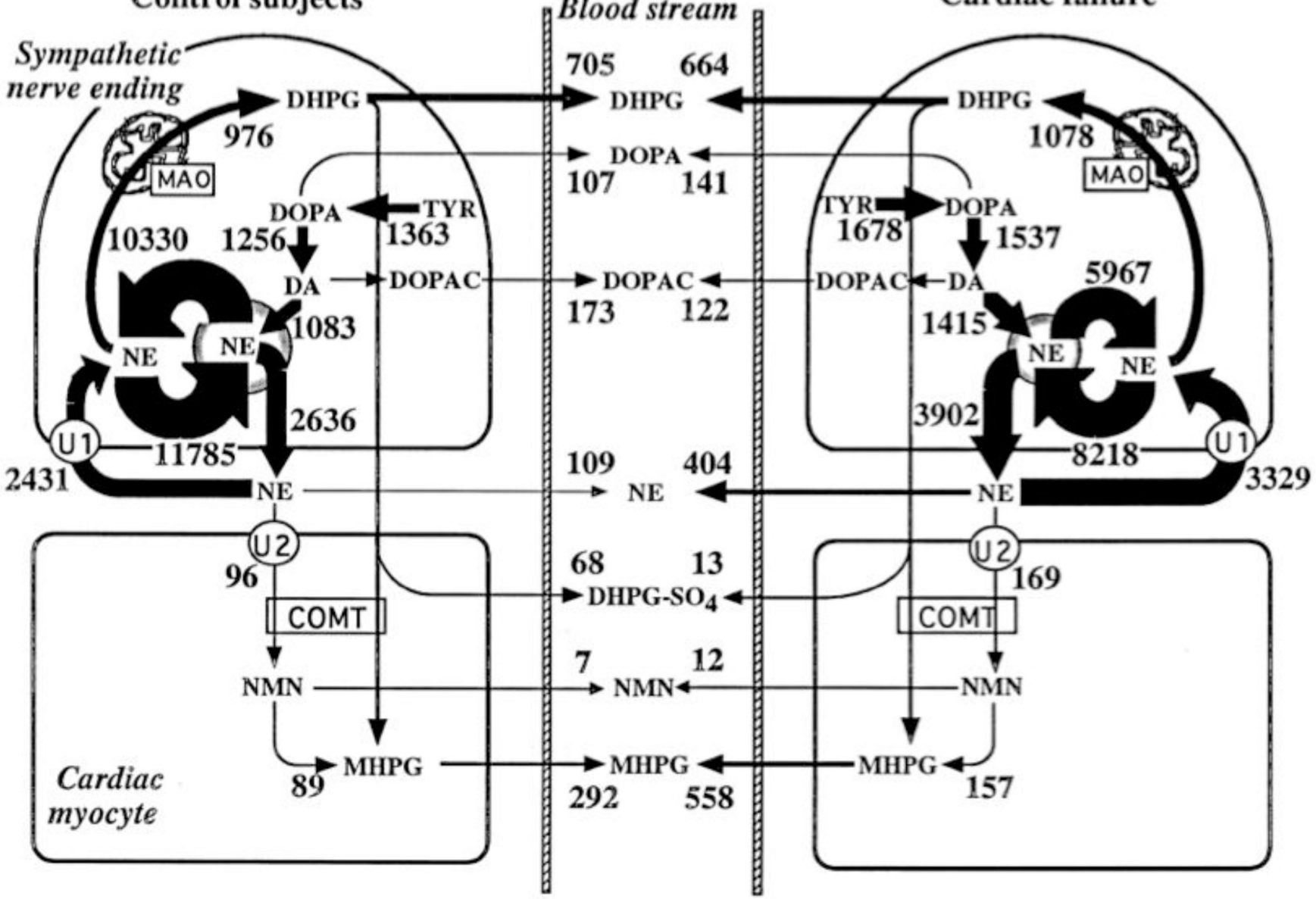

Figure 10. Estimates of rates of norepinephrine synthesis, vesicular recycling, release, neuronal and extraneuronal uptake, and metabolism in cardiac sympathetic nerves in healthy humans and patients with congestive heart failure

Note that under resting conditions most of the turnover of norepinephrine is from net vesicular leakage, not release escaping reuptake. Cardiac norepinephrine spillover is influenced by both exocytotic release and neuronal reuptake. 


\section{Emotional and physical stress}

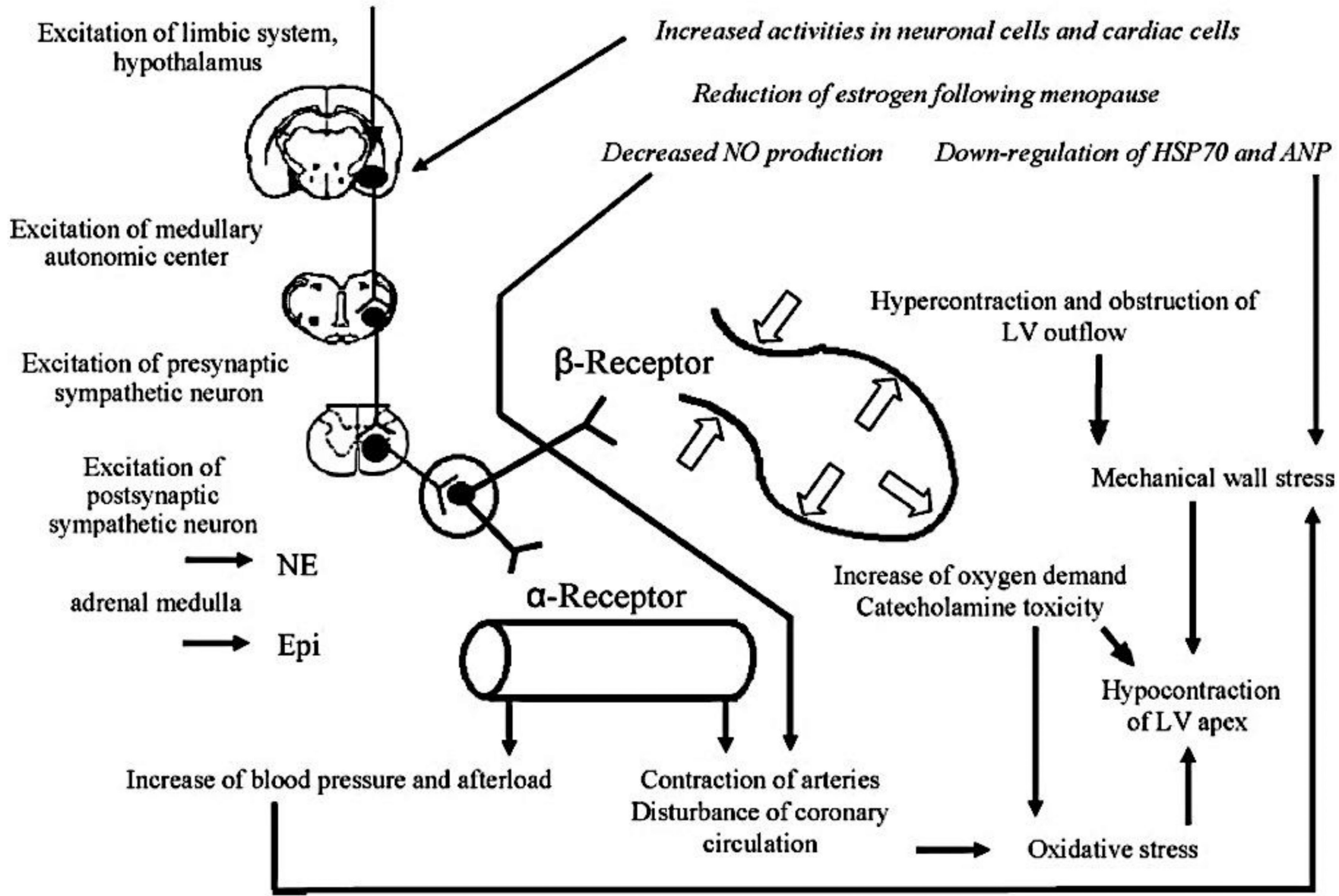

Figure 11. Concept diagram depicting proposed mechanisms of takotsubo cardiopathy (stress cardiopathy) 


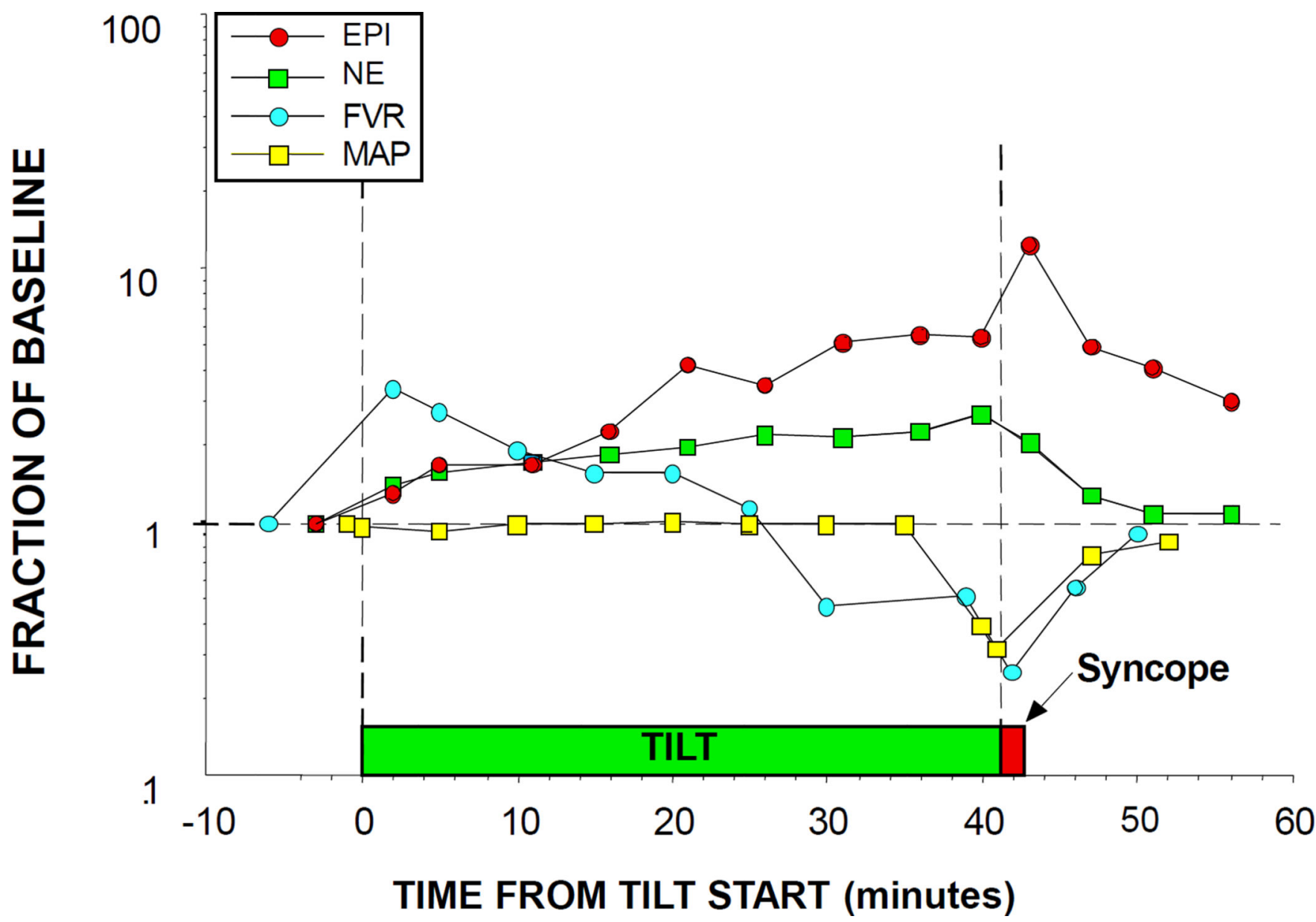

Figure 12. Plasma epinephrine (EPI), norepinephrine (NE), forearm vascular resistance (FVR), and mean arterial pressure (MAP) responses to tilt table testing in a patient with neurocardiogenic syncope

Note progressive decrease in FVR and increase in EPI prior to hypotension and syncope.

Divergence of EPI from NE responses indicates sympathoadrenal imbalance. 

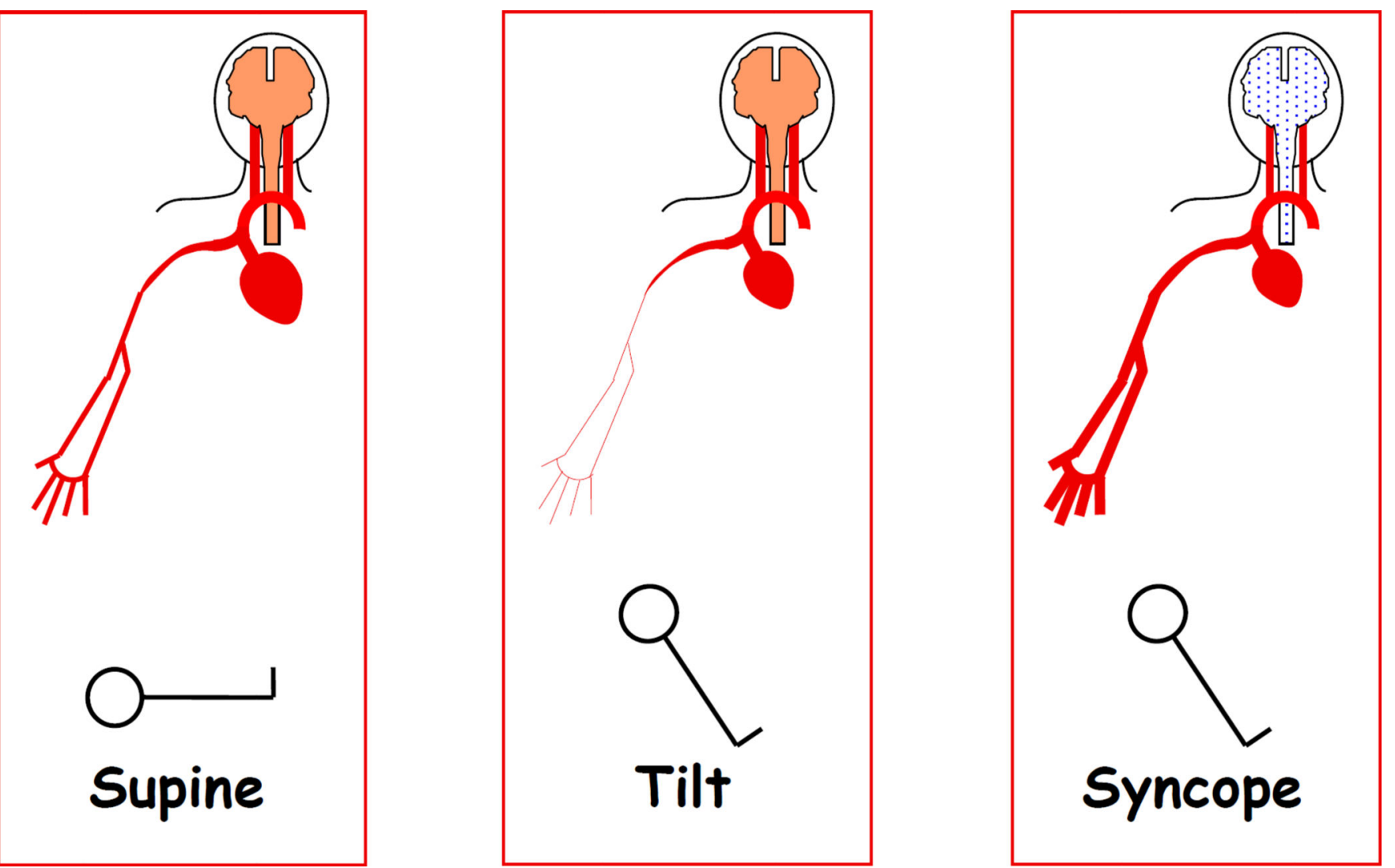

Figure 13. Concept diagram for shifts in blood flow distribution associated with tilt-induced syncope

The normal response to head-up tilting includes sympathetically mediated skeletal muscle vasoconstriction, which counters decreased cardiac output and helps preserve cerebral blood flow. Skeletal muscle vasodilation combined with decreased cardiac output decreases brainstem perfusion, evoking syncope. 


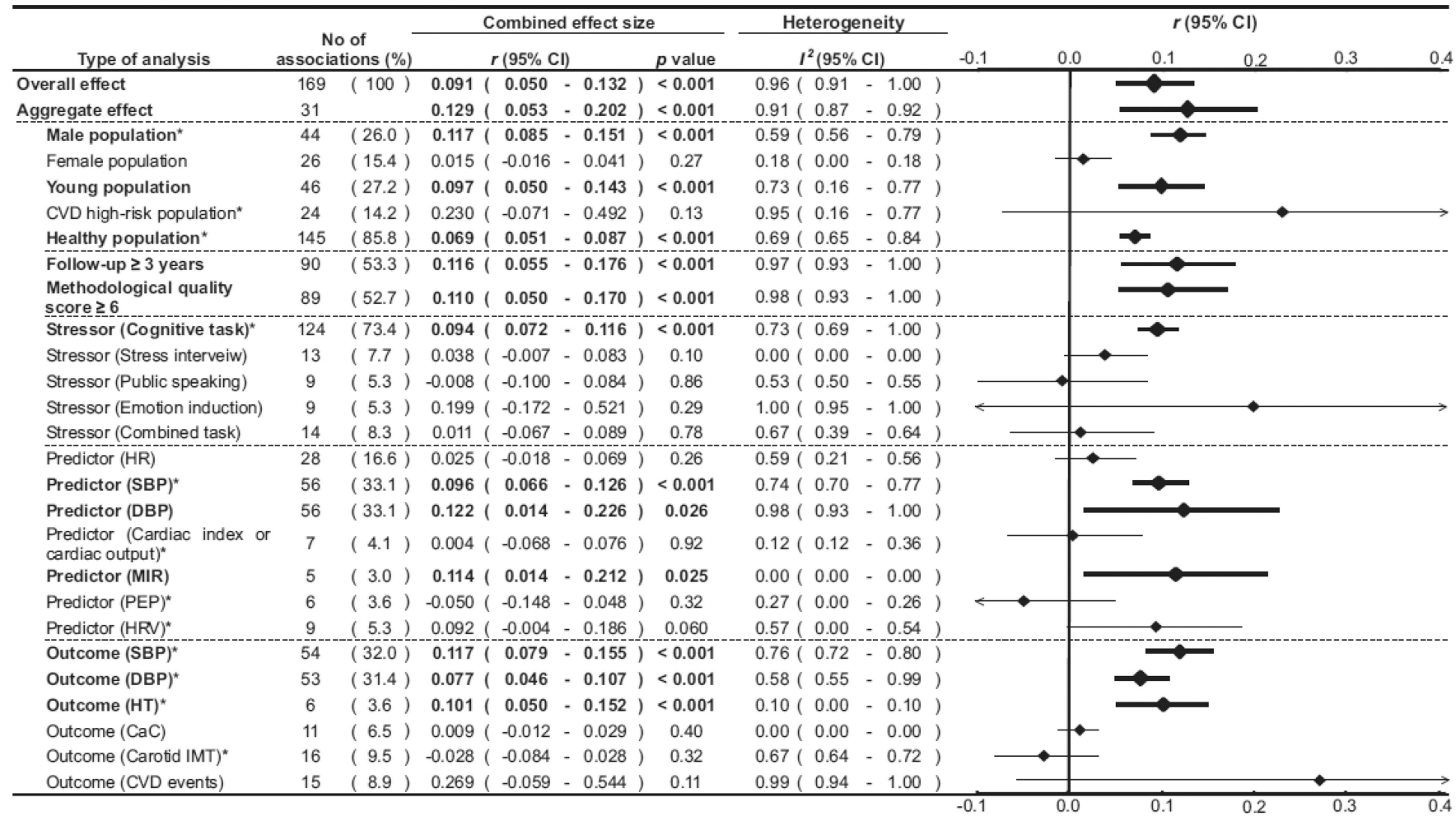

Figure 14.

Meta-analysis from of prospective studies examining cardiovascular reactivity to stress and subsequent cardiovascular status. Taken with permission from Chida \& Steptoe [71]. 


\begin{tabular}{|c|c|c|c|c|c|c|c|c|c|c|c|c|c|}
\hline \multirow[b]{2}{*}{ Type of analysis } & \multirow{2}{*}{\multicolumn{2}{|c|}{$\begin{array}{c}\text { No of } \\
\text { associations } \\
(\%)\end{array}$}} & \multicolumn{4}{|c|}{ Combined effect size } & \multirow{2}{*}{$\begin{array}{l}\text { Heterogeneity } \\
\mathcal{F}^{2}(95 \% \mathrm{Cl})\end{array}$} & \multicolumn{6}{|c|}{$r(95 \% \mathrm{Cl})$} \\
\hline & & & & $r(95 \% \mathrm{C}$ & & $p$ value & & -0.1 & 0.0 & 0.1 & 0.2 & 0.3 & 0.4 \\
\hline Overall effect ${ }^{*}$ & 30 & $(100)$ & 0.096( & 0.058 & $-0.134)$ & $<0.001$ & $0.44(0.42-0.94)$ & & & & & & \\
\hline Aggregate effect ${ }^{\star}$ & 5 & & 0.081( & 0.009 & $=0.151)$ & 0.027 & $0.00(0.00-0.00)$ & & & & & & \\
\hline Follow-up $\geq 3$ years ${ }^{*}$ & 24 & $(80.0)$ & 0.082( & 0.043 & $-0.120)$ & $<0.001$ & $0.43(0.40-0.47)$ & & & & & & \\
\hline $\begin{array}{l}\text { Methodological quality } \\
\text { score } \geq 6^{*}\end{array}$ & 23 & $(76.7)$ & 0.079( & 0.041 & $-0.118)$ & $<0.001$ & $0.43(0.41-0.55)$ & & & & & & \\
\hline Stressor (Cognitive task) & 19 & $(63.3)$ & 0.109( & 0.050 & -0.167 ) & $<0.001$ & $0.58(0.55-0.87)$ & & & & & & \\
\hline Predictor (HR) & 7 & $(23.3)$ & 0.114( & 0.050 & $-0.177)$ & $<0.001$ & $0.00(0.00-0.00)$ & & & & & & \\
\hline Predictor (SBP) ${ }^{\star}$ & 7 & $(23.3)$ & 0.130( & 0.048 & $=0.210)$ & 0.002 & $0.52(0.49-0.48)$ & & & & & & \\
\hline Predictor (DBP) & 8 & $(26.7)$ & 0.073( & -0.007 & $-0.152)$ & 0.074 & $0.50(0.48-0.76)$ & & & & & & \\
\hline Predictor (HRV) & 4 & $(13.3)$ & 0.046( & -0.055 & $-0.146)$ & 0.37 & $0.00(0.00-0.00)$ & & & & & & \\
\hline Outcome (SBP) & 10 & $(33.3)$ & 0.083( & 0.014 & $-0.150)$ & 0.018 & $0.56(0.54-0.59)$ & & & & & & \\
\hline Outcome (DBP) $)^{\star}$ & 10 & $(33.3)$ & 0.083( & 0.032 & $-0.133)$ & 0.001 & $0.21(0.20-0.22)$ & & & & & & \\
\hline Outcome (Carotid IMT) & 9 & $(30.0)$ & 0.140( & 0.045 & -0.233 ) & 0.004 & $0.28(0.27-0.29)$ & & & & & & \\
\hline
\end{tabular}

Figure 15.

Meta-analysis from of prospective studies examining cardiovascular recovery from stress and subsequent cardiovascular status. Taken with permission Chida \& Steptoe [71]. 


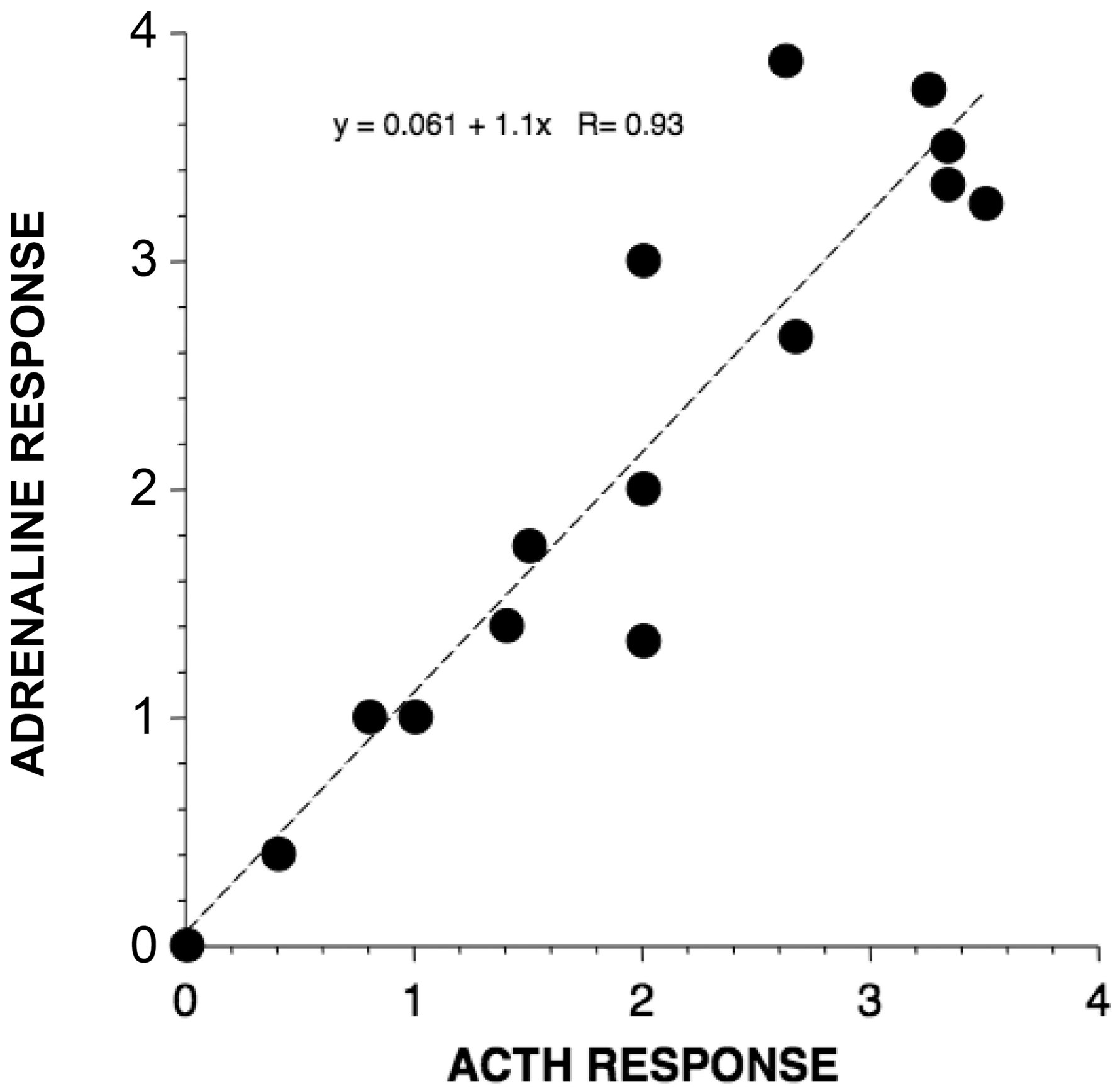

Figure 16. Adrenaline and ACTH responses to different stressors in humans, from a metaanalysis of the literature

There is excellent agreement between adrenomedullary and adrenocortical activation. For instance, exposure to cold exerts little or no adrenomedullary or adrenocortical activation, whereas insulin-induced hypoglycemia evokes large-magnitude adrenomedullary and adrenocortical activation. 
Table 1

Laboratory manipulations for acute mental stress in rodents.

\begin{tabular}{l}
\hline Air-jet stress \\
Restraint or immobilization \\
Dirty cage switch \\
Shaking platform \\
Electric shock of tail or foot \\
Forced swimming \\
Sleep deprivation \\
Noise exposure \\
Cold exposure \\
Resident-intruder/social-defeat \\
\hline
\end{tabular}

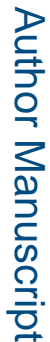

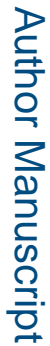

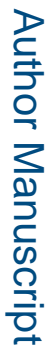

Compr Physiol. Author manuscript; available in PMC 2017 January 30. 


\section{Table 2}

Laboratory manipulations to evoke acute mental stress in humans.

\begin{tabular}{l}
\hline Mental arithmetic \\
Stroop color word conflict test \\
Speech task \\
Delayed auditory feedback \\
International Affective Picture System \\
Exercise anticipation \\
$3^{\text {rd }}$ molar extract anticipation \\
\hline
\end{tabular}




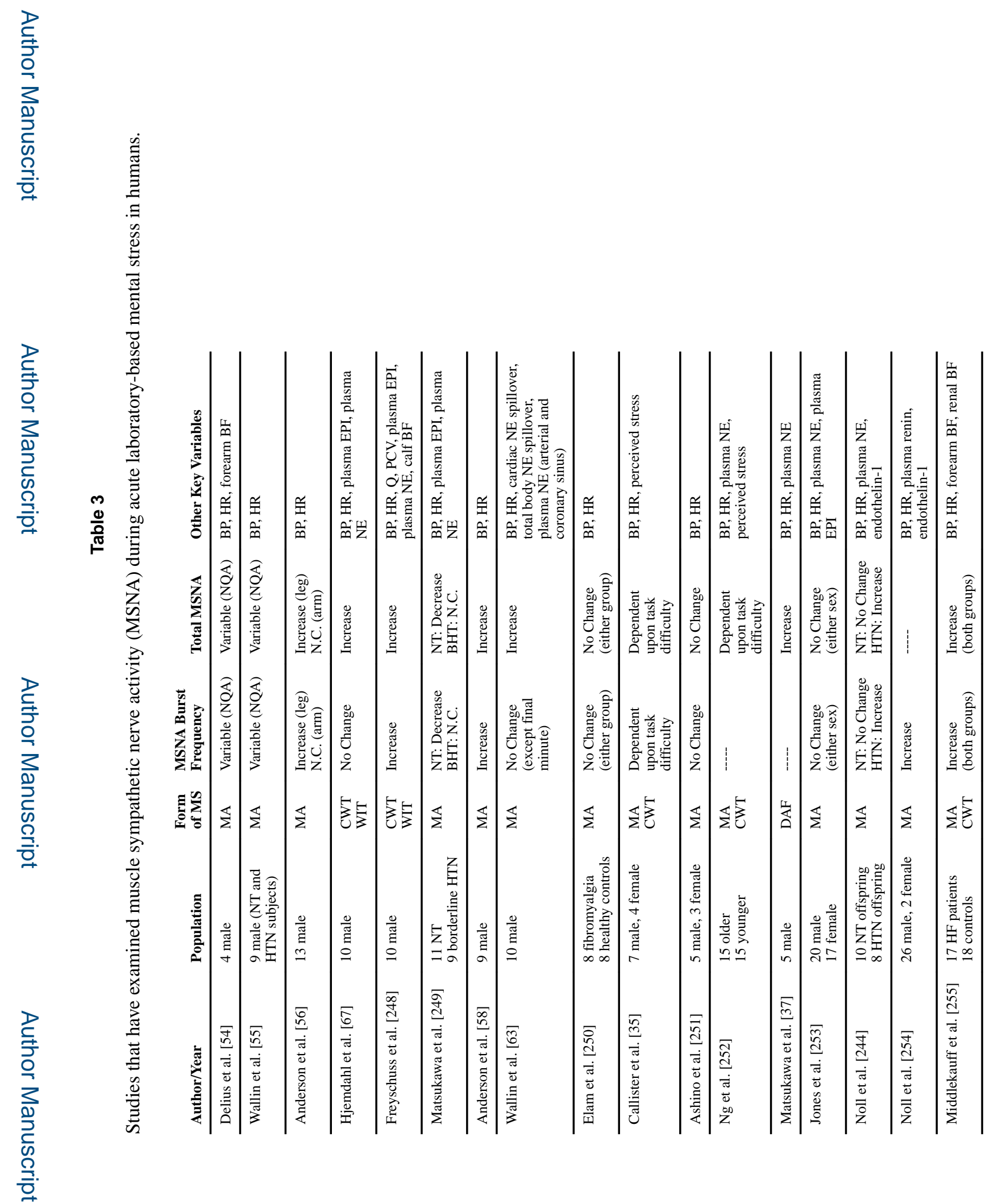




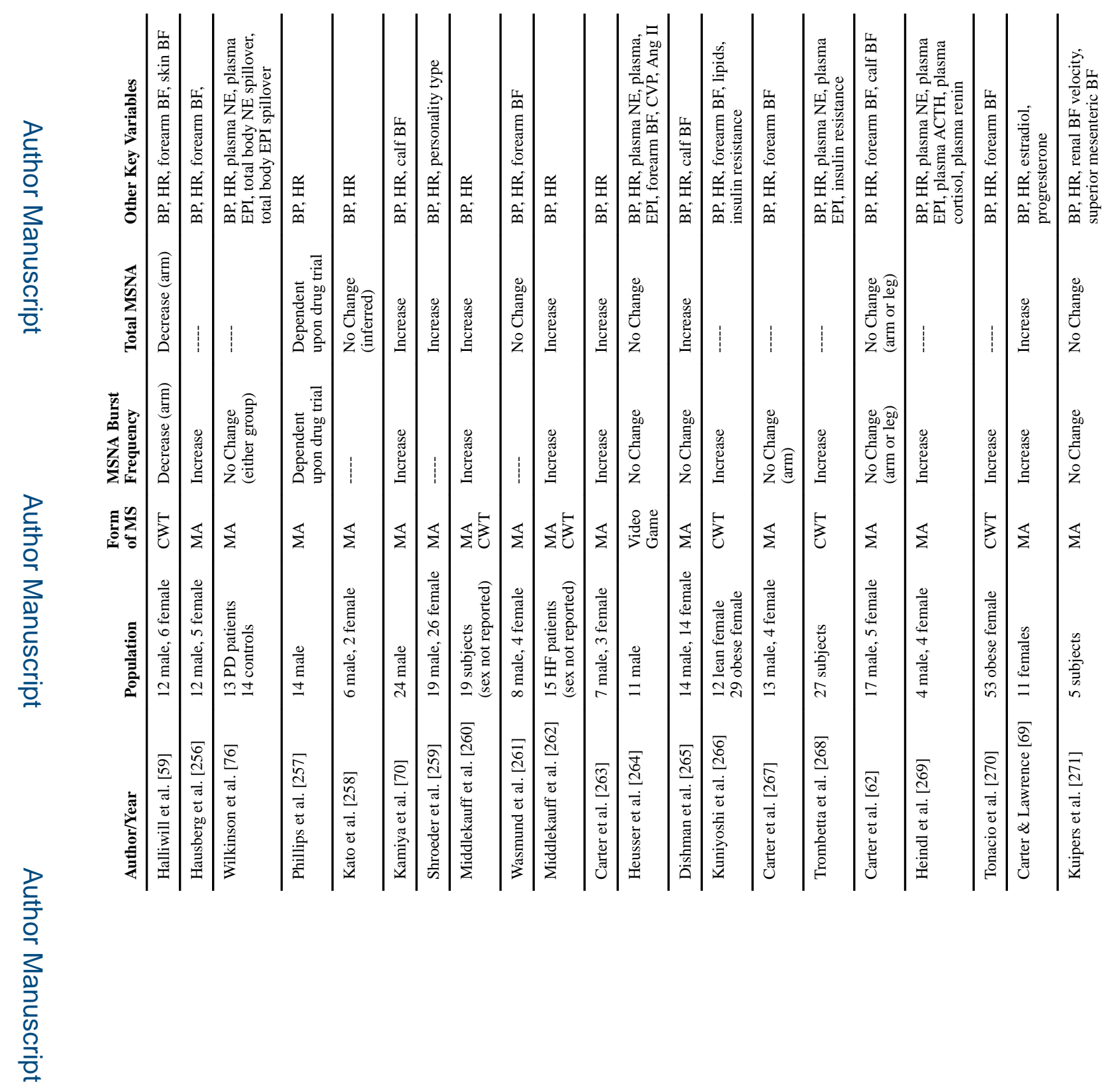

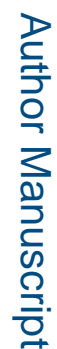




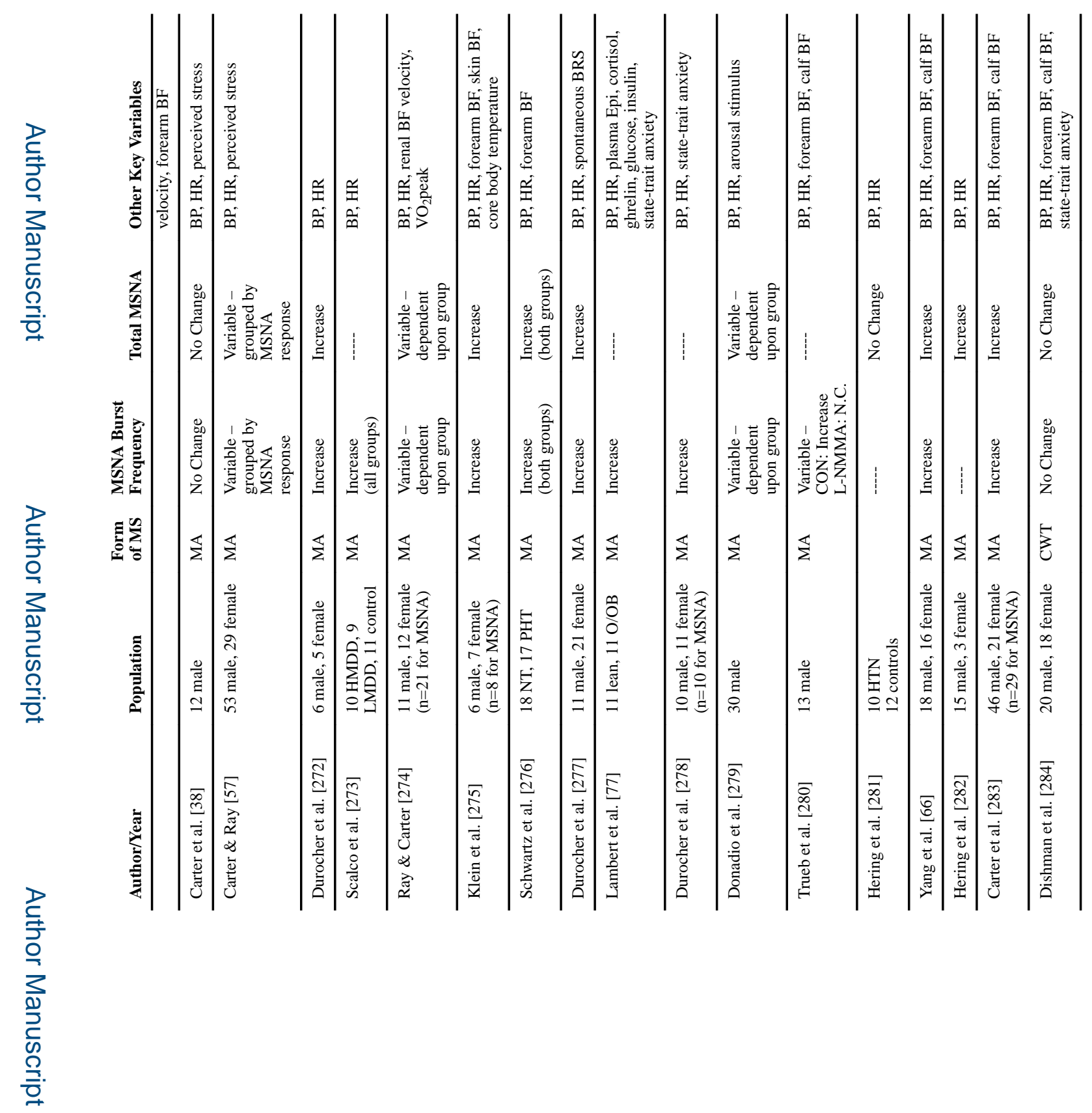

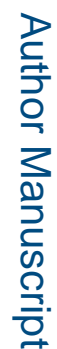




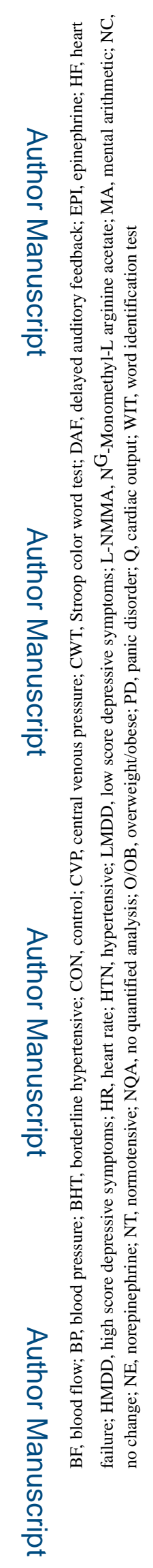

